\title{
A new aircraft architecture based on the ACHEON Coanda effect nozzle: flight model and energy evaluation
}

\author{
Michele Trancossi $^{1} \cdot$ Mauro Madonia $^{2} \cdot$ Antonio Dumas $^{2} \cdot$ Diego Angeli $^{2}$. \\ Chris Bingham ${ }^{3} \cdot$ Shyam Sumanta Das ${ }^{4}$. Francesco Grimaccia ${ }^{5,6}$. \\ Jose Pascoa Marques ${ }^{4} \cdot$ Eliana Porreca $^{7}$. Tim Smith ${ }^{3}$ - Paul Stewart ${ }^{8}$. \\ Maharshi Subhash $^{2} \cdot$ Anna Sunol $^{9} \cdot$ Dean Vucinic ${ }^{9}$
}

Received: 6 December 2014 / Accepted: 10 February 2016 / Published online: 12 March 2016

(C) The Author(s) 2016. This article is published with open access at SpringerLink.com

\begin{abstract}
Purpose Aeronautic transport has an effective necessity of reducing fuel consumption and emissions to deliver efficiency and competitiveness driven by today commercial and legislative requirements. Actual aircraft configurations scenario allows envisaging the signs of a diffused technological maturity and they seem very near their limits. This scenario clearly shows the necessity of radical innovations with particular reference to propulsion systems and to aircraftarchitecture consequently.

Methods This paper presents analyses and discusses a promising propulsive architecture based on an innovative nozzle,
\end{abstract}

Michele Trancossi

m.trancossi@shu.ac.uk

1 ACES, Sheffield Hallam University, City Campus, Howard Street, Sheffield S1 1WB, UK

2 Università di Modena e Reggio Emilia, Di.S.M.I., Via Amendola, 2, 42100 Reggio Emilia, Italy

3 School of Engineering, Brayford Pool, University of Lincoln, Lincoln LN6 7TS, UK

4 Faculty of Engineering, Convento de Santo António, Universidade da Beira Interior, 6201-001 Covilhã, Portugal

5 Nimbus srl, Lombardore, Torino, Italy

6 Dipartimento di Energia, Politecnico di Milano, Campus Bovisa - Via La Masa, 34, 20156 Milan, Italy

7 Reggio Emilia Innovazione, via Sicilia 31, 42122 Reggio Emilia, Italy

8 Institute for Innovation in Sustainable Engineering, University of Derby, Lonsdale House, Quaker Lane, Derby DE1 3HB, UK

9 Department of Mechanical Engineering, Vrije Universiteit Brussel, Triomflaan 43 - Room TL43/2.12, B-1050 Brussels, Belgium which allows realizing the selective adhesion of two impinging streams to two facing jets to two facing Coanda surfaces. This propulsion system is known with the acronym ACHEON (Aerial Coanda High Efficiency Orienting Nozzle). This paper investigates how the application of an all-electric ACHEONs propulsion system to a very traditional commuter aircraft can improve its relevant performances. This paper considers the constraints imposed by current state-of-the-art electric motors, drives, storage and conversion systems in terms of both power/energy density and performance and considers two different aircraft configurations: one using battery only and one adopting a more sophisticated hybrid cogeneration. The necessity of producing a very solid analysis has forced to limit the deflection of the jet in a very conservative range $\left( \pm 15^{\circ}\right)$ with respect to the horizontal. This range can be surely produced also by not optimal configurations and allow minimizing the use of DBD. From the study of general flight dynamics equations of the aircraft in two-dimensional form it has been possible to determine with a high level of accuracy the advantages that ACHEON brings in terms of reduced stall speed and of reduced take-off and landing distances. Additionally, it includes an effective energy analysis focusing on the efficiency and environmental advantages of the electric ACHEON based propulsion by assuming the today industrial grade high capacity batteries with a power density of $207 \mathrm{Wh} / \mathrm{kg}$.

Results It has been clearly demonstrated that a short flight could be possible adopting battery energy storage, and longer duration could be possible by adopting a more sophisticated cogeneration system, which is based on cogeneration from a well-known turboprop, which is mostly used in helicopter propulsion. This electric generation system can be empowered by recovering the heat and using it to increase the temperature of the jet. It is possible to transfer this considerable amount of heat to the jet by convection and direct fluid mixing. In this way, it is possible to increase the energy of the jets of an 
amount that allows more than recover the pressure losses in the straitening section. In this case, it is then possible to demonstrate an adequate autonomy of flight and operative range of the aircraft. The proposed architecture, which is within the limits of the most conservative results obtained, demonstrates significant additional benefits for aircraft manoeuvrability. In conclusion, this paper has presented the implantation of ACHEON on well-known traditional aircraft, verifying the suitability and effectiveness of the proposed system both in terms of endurance with a cogeneration architecture and in terms of manoeuvrability. It has demonstrated the potential of the system in terms of both takeoff and landing space requirements.

Conclusions This innovation opens interesting perspectives for the future implementation of this new vector and thrust propulsion system, especially in the area of greening the aeronautic sector. It has also demonstrated that ACHEON has the potential of renovating completely a classic old aircraft configuration such as the one of Cessna 402.

Keywords Aerial propulsion - Coanda · Energy efficiency · Energy model $\cdot$ Flight model $\cdot$ Short takeoff and landing

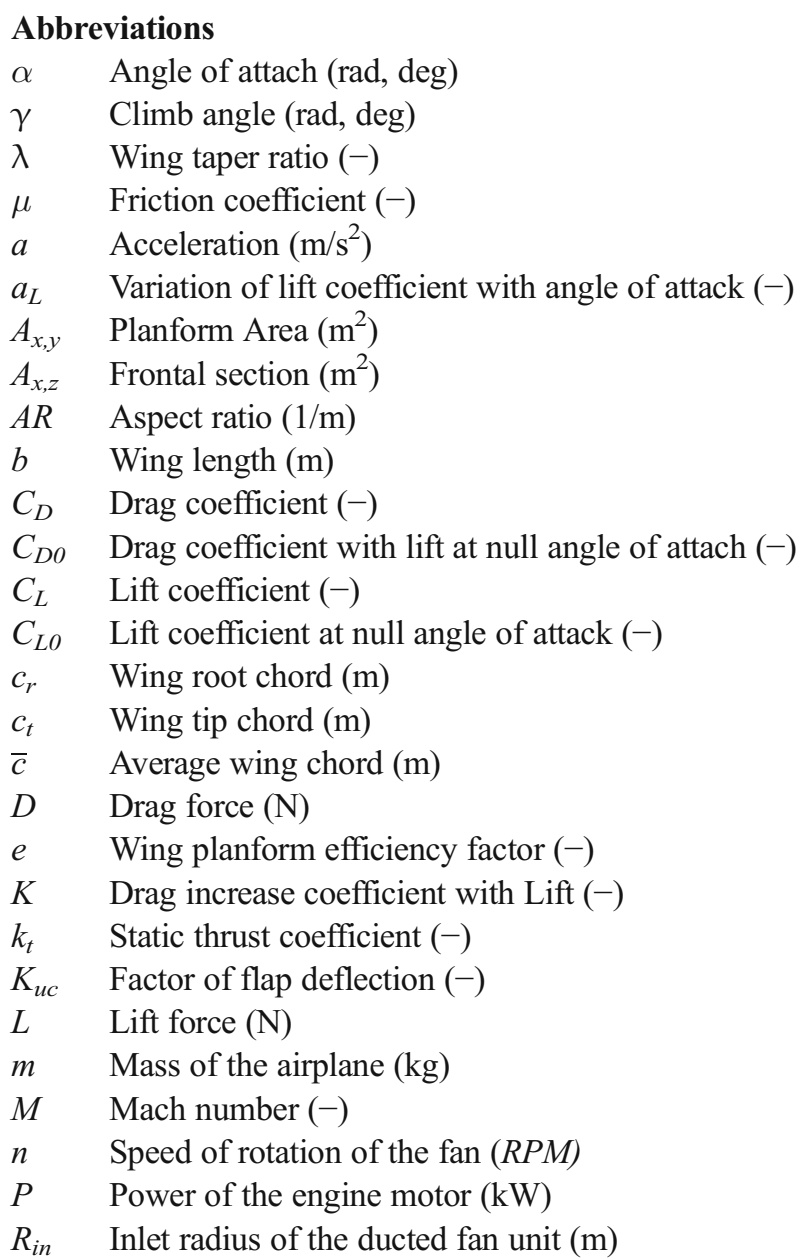

$R_{m} \quad$ Radius of the motor (m)

$R_{\text {out }} \quad$ Outlet radius of the ducted fan unit (m)

$R_{f} \quad$ Fan radius of the ducted fan unit (m)

$S \quad$ Wing planform area $\left(\mathrm{m}^{2}\right)$

$t \quad$ Angle of thrust (rad)

$T \quad$ Thrust (N)

$u \quad$ Aircraft speed $(\mathrm{m} / \mathrm{s})$

$u_{\text {stall }} \quad$ Aircraft stall speed $(\mathrm{m} / \mathrm{s})$

$V_{\text {exit }} \quad$ Air speed at the outlet of the ducted fan unit

$W \quad$ Weight $(\mathrm{kg})$

$W / S \quad$ Wing loading $\left(\mathrm{N} / \mathrm{m}^{2}\right)$

\section{Introduction}

\subsection{Generalities}

The future of the aeronautic domain is predicated on the necessity to meet public and legislative demand in terms of increased safety and capacity, reduced emissions and noise, higher manoeuvrability and increased flexibility of use, reduced time for travel and take off, and reduced landing space requirements. For example, NASA has launched the 'Revolutionize Aviation' program, demonstrating that 'game-changing' novel propulsion systems are necessary to enable the design of revolutionary aircraft that could meet future and greener needs [1].

The ACHEON (Aerial Coanda High Efficiency Orientingjet Nozzle) [2] is a new propulsive architecture that aims to fulfil most of these goals. It defines a novel class of aerial vehicles, which are green, all electric, with improved manoeuvrability, reduced takeoff, and landing spaces. Cen et al. [3] have verified that this system has the potential of increasing the manoeuvrability of a high performance jet with a significant increase in performance.

This paper considers a more conservative domain. It aims to verify how ACHEON can be implemented inside the architecture of a traditional twin-engine transport aircraft and analyzes the benefits and the feasibility of the system. A novel class of transport aircraft, which is designed to benefit of ACHEON nozzle, is subsequently defined inside this paper.

\subsection{ACHEON nozzle architecture}

ACHEON nozzle has been defined by Trancossi [4] as a twostream nozzle, which has the ability of deflecting the resulting synthetic jet by means of the Coanda Effect. This result has produced a patent by Università di Modena e Reggio Emilia $[5,6]$. The patent has been initially presented by Trancossi and Dumas $[7,8]$. This preliminary investigation has evidenced the main advantage of the system, which is the extraordinary reactivity and velocity of response, and the main constraint of the system that relates to its intrinsic instability. In particular, 
subsequent to investigating the stability problem, the project has integrated the Coanda effect nozzle with a dielectric barrier discharge (DBD) to increase the stability of the system, as defined by Cattafesta [9] and improved by Xisto [10].

The architecture of the nozzle as originally defined by the patent is represented in Fig. 1.

The ACHEON nozzle (1) is capable of mixing two primitive fluid jets (2) and (2') and producing a selective and controllable angular deviation of the synthetic jet (7) without any moving mechanical part. The nozzle (1) is also capable of changing the direction of this jet in a continuous and dynamic manner to allow the jet to sweep a preset and arbitrary angle. The nozzle (1) is constituted, in a first part thereof, by a conduit (8) divided into two channels by a central baffle (9) and, in a second part thereof, by a convergence zone and an outflow mouth (5) whose walls have a curvilinear profile and are connected seamlessly to the walls of the conduit. Dragan [11] has independently validated the preliminary Coanda effect model by Trancossi and Trancossi and Dumas.

A general overview has been produced by Dumas et al. [12]

\subsection{Coanda effect modelling}

Significant research activity has been conducted on Coanda effect modelling and analysis. In particular, Trancossi, Dumas et al. [13] produced a theoretical model of Coanda attachment mechanisms and the laws of the Coanda effect. The proposed model has been realized by integration of Navier Stokes equations starting from the Dragan [14] model. The authors consider a very conventional setup in order to define by a theoretical analysis a mathematical model of the Coanda adhesion and define a preliminary model, which could be suitable for simple engineering calculations and preliminary comprehension of the model by elementary equations. A parametric model has defined as a function of the main cinematic and geometric parameters. The final model relates to three

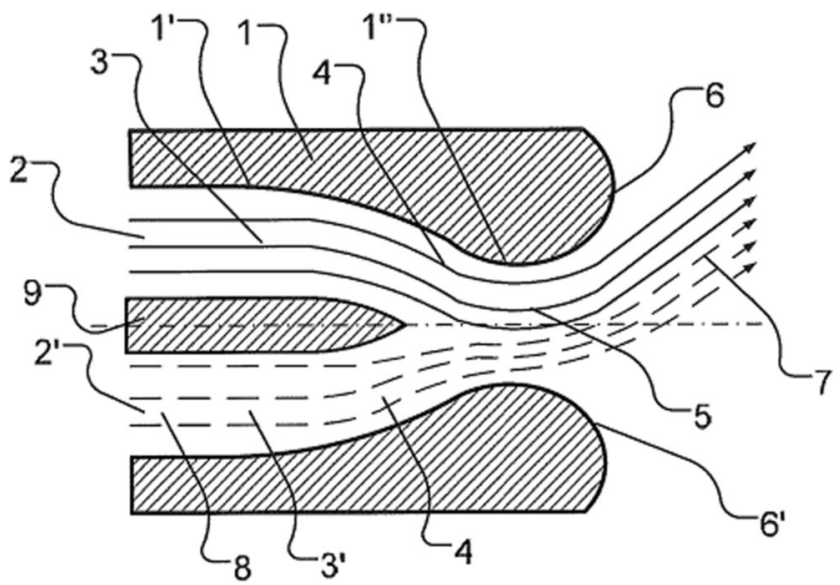

Fig. 1 Original nozzle architecture (from Patent WO/2013/005132) fundamental parameters: outlet section, Coanda surfaces radius and inlet velocities. Turbulent and laminar models have been defined. Validation through a large CDF development programme has been produced in a regime of stream velocities from 5 to $40 \mathrm{~m} / \mathrm{s}$ with good correlation results.

This activity has been improved by Subhash and Dumas [15], who have produced a large set of numerical computations with different turbulence models on an air jet flowing tangentially over the curved surface. In particular, they have obtained that without resolution of the viscous sub-layer, since it is not possible to determine the computationally independent angle of jet deflection and boundary layer thickness. The boundary layer analysis has been performed at different radius of curvatures and at jet Reynolds numbers ranging from approximately about $2400-10,000$. The skin-friction coefficient has been also studied at the separation in relation to the surface radius and jet Reynolds number. In this research work, the inter-relation between flow and geometric parameters has been identified for the further design of the Coanda nozzle flow.

Dumas, Subhash at al. [16] have analysed the effect of the temperature of the surface on the Coanda effect adhesion. This activity has led to the identification of a negative effect of heated Coanda surfaces on the adhesion phenomena.

Das at al. [17] have carried out numerical simulations to investigate Coanda flow over a curved surface and analysed the application to the ACHEON system. He has observed the effect of Dielectric barrier discharge (DBD) plasma actuators, concluding that it has an effective capacity both of stabilizing the behaviour of the system and of increasing the angle of adhesion. CFD computations were performed under subsonic condition by Reynolds averaged Navier stokes equations (RANS).

\subsection{Coanda nozzle modelling}

After preliminary analysis by Trancossi and Dumas, a more focused activity has been performed on the nozzle. Trancossi, Subhash et al. [18] has analysed the ACHEON Coanda effect based propulsion nozzle for aircraft propulsion considering the dynamic equilibrium of two jet streams and explain how the Constructal Optimization process allowed the preliminary definition of the nozzle. The model has been produced by assuming an inviscid model. A preliminary mathematical model of a 2D case of the system has been developed, focusing on the combined effect of the mixing effect of the two streams and the Coanda Effect Adhesion over a convex surface. Trancossi et al. [19] have specifically modelled the ACHEON Coanda effect two streams nozzle. The paper tries to produce an effective design guideline, which can be adopted for design activities of the nozzle for aeronautic propulsion. The presented model allows the definition of a governing method for this innovative two-stream synthetic 
jet nozzle. The uncertainness levels of the model are discussed and novel aircraft architectures based on it are presented. A CFD validation programme is presented focusing on validating the model and the designs produced. Pascoa et al. [20] have produced an effective bibliographic analysis on thrust deflection systems producing an effective comparison with other thrust and vector system.

\subsection{Dielectric barrier discharge}

The Dielectric barrier concept and architecture, which are used in the ACHEON nozzle, are derived directly from the one defined by Pascoa et al. [21] in 2009, and is presented in Fig. 2. Abdollahzadeh and Pascoa [22] introduced a generic analytical approach that can be used to predict analytically the momentum transfer in DBDs, allowing a better analytical analysis of the dynamic behaviour of the ACHEON nozzle.

Abdollahzadeh et al. [23] have explored the use of thermal DBDs. Until the moment, only non-thermal DBDs have been used for ACHEON, due to the lower flow speeds involved. This is a general paper dealing with the numerical modelling of nanosecond pulse micro-shock wave plasma actuators. As verified by Subhash et al. thermal effects are negative at low Reynolds number, but becomes an effective solution at high Mach numbers, including transonic or supersonic conditions.

\section{Definition of the problem}

\subsection{Generalities}

Sunol and Vucinic [24] have started a preliminary analysis of integration of the ACHEON nozzle into an aerial Vehicle. Building upon this preliminary result, this paper aims to analyze how the ACHEON nozzle can be further integrated into aircraft architecture, and in particular will focus on the definition of a specific aircraft model taking maximum advantage of this nozzle.

Current S-VTOL aircraft are generally not optimized designs because they are based on very traditional aircraft architectures not specifically designed for this kind of operation. The design optimization will focus on a simplified 2D plane of motion considering initially only the advantage during take off, climbing and landing operations.
Four forces act on an aircraft in flight: lift, weight, thrust, and drag. For an aircraft in cruise, the four forces are balanced, and the aircraft moves at a constant velocity and altitude. Any altitude change makes them diverge from equilibrium. Vertical and horizontal axes of the aircraft have their origin in the center of gravity. Two flight paths are designed as red and blue lines inclined to the horizontal at angle $c$ as in Fig. 3. Take off and landing operation will be evaluated.

The results obtained allow the definition of a configuration that allows the installation of ACHEON on a very conservative classical airplane design.

This paper will analyze flight mechanics problems starting from a rigorous Newtonian approach, considering basic equations derived from Newton's second law. to enable analysis and understanding of the benefits of the ACHEON nozzle under different conditions.

Preliminary calculations will be performed assuming the effects of the pitch as included in the Drag and Lift aerodynamic coefficient.

\subsection{Final Remarks about methodology}

Because of the methodological analysis performed, some theoretical benefits have clearly been shown. This analysis and FAR regulations enables the production of an effective mission analysis based on a real plane model.

The characteristics of flight related to the considered potential ACHEON applications inside the project are restricted to subsonic airplanes. A significant class of vehicles which has been identified is a twin-engine commuter aircrafts, which are suitable for Corporate transport and airliner up to 9/12 passengers. Cessna 402 and Piper PA 31 Navajo have been considered also because of their constitutive characteristics and design, even if they are not recent designs.

\section{Methodology}

\subsection{Airplane data}

The availability of accessible data makes the Cessna 402 (Fig. 3) the preferred airframe for analysis, also having a wing structure, which simplifies the adoption of ACHEON ducted fan system to replace traditional propulsion. The Cessna 402
Fig. 2 Dielectric Barrier Discharge conceptual design

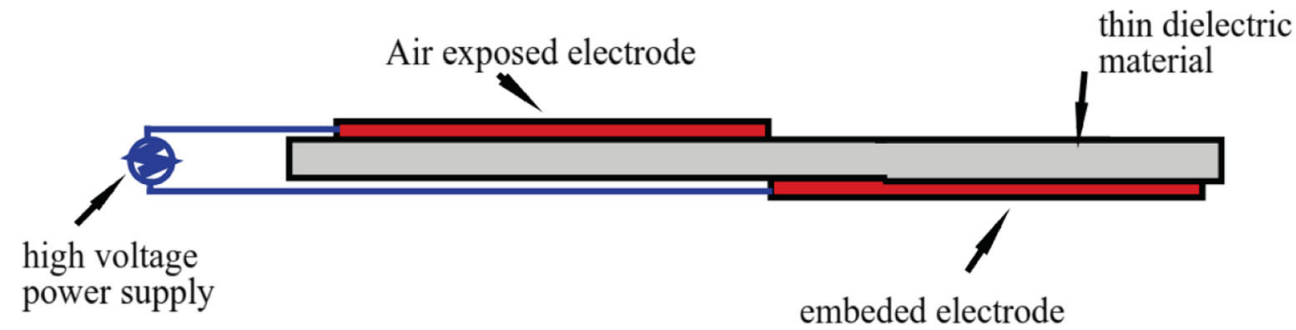




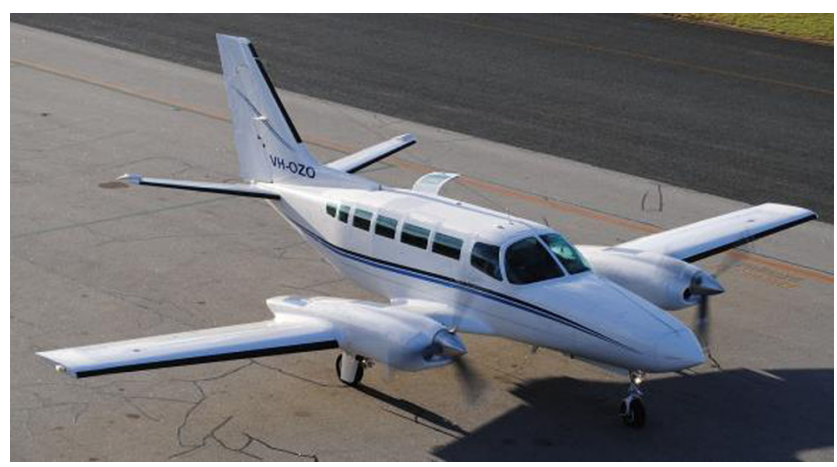

Fig. 3 Cessna 402 during takeoff

with ACHEON propulsion is represented in Fig. 4. Each aircraft is designed in order to satisfy the needs of potential users. Aircraft performance depends mainly on the structural and aerodynamic characteristics, and the features of the system propulsion. Assuming Cessna 402 data, which have been obtained from several sources [25-30], it will be possible to compare a traditional twin-engine aircraft with one propelled by this new propulsion system. .

\subsection{Propulsion and thrust}

Thrust is a mechanical force generated by propulsion, as explained by Newton's third law of motion: if a working fluid is accelerated in rear direction, the aircraft is accelerated in the opposite direction. From Newton's second law of motion, we can define a force $\mathrm{F}$ to be the change in momentum of an object with a change in time. The thrust is equal to

$T=\frac{d}{d t}\left(m_{\text {air }} \cdot v\right)$ considering an inlet section 0 and an exit section e, the force is given by:

$T=\dot{m}_{\text {air }, e} \cdot V_{\text {air }, e}-m_{\text {air }, 0} \cdot V_{\text {air }, 0}$

Considering the additional effect due to the pressure difference between inlet and outlet, an additional force term equal to the exit area $A_{e}$ times the exit pressure minus the free stream pressure must be considered. The general thrust equation is then given by:

$T=\dot{m}_{\text {air }, e} \cdot V_{\text {air }, e}-\dot{m}_{\text {air }, 0} \cdot V_{\text {air }, 0}+\left(p_{e}-p_{0}\right) A_{e}$

Assuming propeller disk model it can be modelled as Substituting the values given by Bernoulli's equation into the thrust equation and results:

$T=0.5 \cdot \rho \cdot A \cdot\left(v_{e}^{2}-v_{0}^{2}\right)$

It is then clear that the relation between propulsive power and thrust is

$T=\eta_{p} \cdot \frac{P}{u}$

where $\eta_{P}$ is the propulsive efficiency.

Characteristic and performance table is reported in Appendix 1, while power propulsion system is evaluated in Table 1. The propeller is schematized in Fig. 5. Main dimensional parameters, which are calculated according to Trancossi et al. [31, 32], are reported in Table 2 and considering a different diameter of the fan. Installing four ducted fan units with a pressure ratio

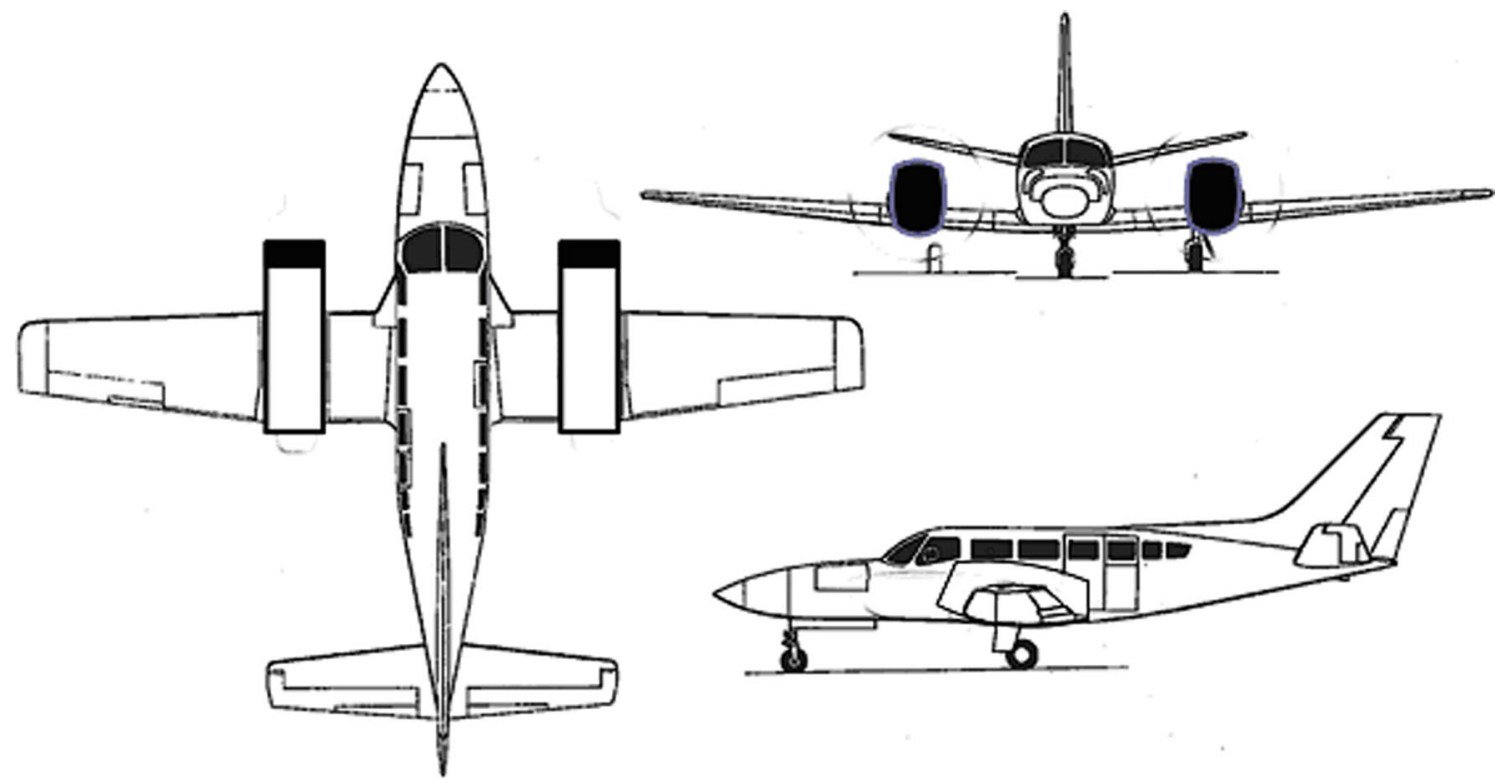

Fig. 4 Cessna 402 modified for installing acheon 
Table 1 Ducted fan dimensions

\begin{tabular}{lll}
\hline$R_{\text {in }}$ & $\mathrm{m}$ & 0.72 \\
$R_{m}$ & $\mathrm{~m}$ & 0.61 \\
$R_{\text {out }}$ & $\mathrm{m}$ & 0.5400 \\
$R_{f}$ & $\mathrm{~m}$ & 0.60 \\
Max rotation speed motor & $\mathrm{rpm}$ & 6000 \\
Speed reduction & - & 2 \\
Voltage & $\mathrm{V}$ & 350 \\
Max Current & $\mathrm{A}$ & 390 \\
\hline
\end{tabular}

1.1, turbofan characteristics can be evaluated according to Mingtai [33] who suggest the relation

$T_{s}=1.238 \cdot 10^{-12} \cdot n^{2} \cdot\left(2 R_{f}\right)^{4} \cdot \rho_{\text {air }} \cdot k_{t}$

where $k_{t}$ is the static thrust coefficient and $n$ is the speed of rotation of the fan.

The advantage supporting the adoption of the Cessna 402 model is the relative high number of aircraft in operation both produced by Cessna and by Sukhoi. It is an aged project, but displays good flight performance and behaviour, which is appreciated by pilots, and the very traditional distribution of weight in the airplane, which fits very well with the use of such propulsion also because of the construction of wings, which could allow a good integration of ACHEON derived propulsion nozzles instead of traditional propulsion.

The ducted fan units have the dimensions specified in Table 1 and performance specified in Table 2. In particular, a turbo machine with a pressure jump $\Delta p=0.3 P_{a t m}$ has been adopted.

The Cessna 402 has a thrust to weight ratio about 0.37 , and a total thrust of approximately $11000 \mathrm{~N}$. The proposed compressor units, to achieve $30 \%$ pressure jump, require multiple stages, typical of turbo machinery. The typical compressor unit has a max thrust about $3000 \mathrm{~N}$, thus there will be 4 compressor units to propel the aircraft with a max thrust about $12000 \mathrm{~N}$.

On this basis, it is possible to evaluate the system. The deflected thrust by Coanda effect is evaluated according to Keen [34], who has verified that it is almost negligible because of very reduced frictional effects, and because a very low lift is produced, in a boxed architecture of the ACHEON nozzle (Fig. 6). Starting from those preliminary evaluations the aircraft system will be evaluated.
Table 2 Aerodynamic parameters

\begin{tabular}{ll}
\hline $\mathrm{C}_{\mathrm{D} 0}$ & 0.027 \\
$\mathrm{E}$ & 7.7 \\
$\mathrm{~K}$ & 0.00617 \\
$\mathrm{C}_{\mathrm{L} 0}$ & 0.167 \\
$\mathrm{C}_{\mathrm{Dmax}}$ & 0.0338 \\
$\mathrm{C}_{\mathrm{Lmax}}$ & 1.104 \\
$\mathrm{C}_{\mathrm{Lmax}, \text { carriage }}$ & 0.0415 \\
$\mathrm{C}_{\mathrm{Lmax} \text { carriage }}$ & 2.35 \\
$W_{\text {TOmax }} / S$ & 185.86 \\
$T_{S L} / W_{\text {TOmax }}$ & 1.67 \\
\hline
\end{tabular}

\subsection{Wing characteristics}

The wing planform area (S) is shaded in Fig. 6. The wing taper ratio is assumed to be the ratio of tip chord $\left(c_{t}\right)$ to root chord $\left(c_{r}\right)$,

$\lambda=\frac{c_{t}}{c_{r}}$

The mean aerodynamic chord can be found by integrating the individual section chords across the span.

$\bar{c}=\frac{2}{S} \cdot \int_{0}^{b / 2} c^{2} \cdot d y$

In case of wings with simple linear taper. In this case, the mean aerodynamic chord will roughly equal the mean geometric chord,

$\bar{c}=c_{\text {avg }}=\frac{S}{b}$

The aspect ratio of the external wing parts will be,

$A R=\frac{b^{2}}{S}$

moreover, for the central rectangular planform this simplifies to,

$A R=\frac{b}{c}$

In the case of Cessna 402, wing area is about $21 \mathrm{~m}^{2}$. Aspect ratio of Cessna 402 is 8.61 .

Fig. 5 Propeller schema

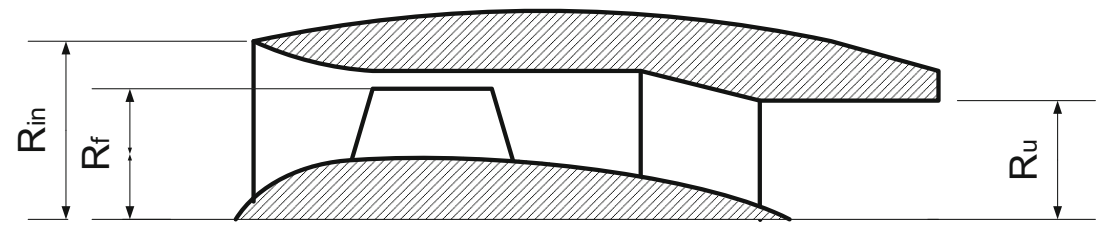




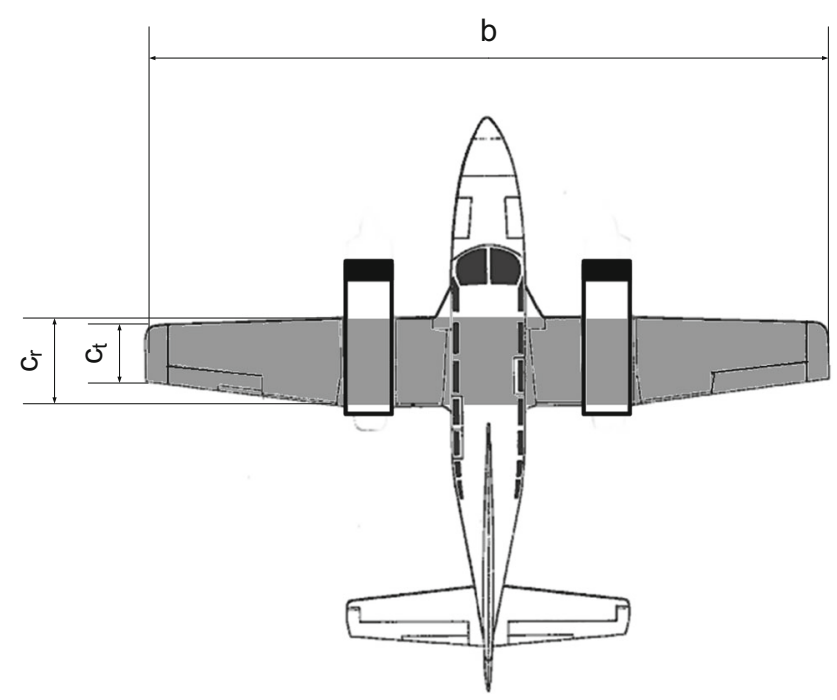

Fig. 6 Wing area (colored in gray)

\subsection{Lift and lift coefficient}

To simplify the problem, lift is typically measured as a nondimensional coefficient.

$C_{L}=\frac{L}{0.5 \cdot \rho \cdot u^{2} \cdot A_{p}}$

In the normal range of operations, the variation of lift coefficient with angle of attack of the vehicle will be approximately linear,

$C_{L}=a_{L} \cdot \alpha+C_{L o}=a_{L} \cdot\left(\alpha-\alpha_{o}\right)$

until a maximum lift coefficient value at which point the wing flow stalls and lift reduces.

A simple approximation for straight, moderate to high aspect ratio wings is to assume an elliptical spanwise load distribution, which gives the following result,

$a=\frac{d C_{L}}{d \alpha}=C_{L \alpha}=\frac{2 \cdot \pi}{1+\frac{2}{A R}}$

where it is assumed that the ideal two-dimensional result for the section used is $2 \pi$.

Calculation of zero angle lift coefficient or zero lift angle can be done by crudely assuming that the zero lift angle for the aircraft equals the combination of zero lift angle of the aerofoil section and wing incidence setting. Calculation of maximum lift coefficient can be approximately equal to the two dimensional section data minus $5 \%$ due to the negative lift needed at the tailplane to maintain moment equilibrium. These approximations works properly for the Cessna 402 because of it has almost rectangular wings.

\subsection{Drag coefficient}

In theory the drag can be predicted by using a simple parabolic drag assumption,

$C_{D}=C_{D 0}+K\left(C_{L}-C_{L 0}\right)^{2}$

If the offset due to camber is neglected, the following simplified equation can be obtained

$C_{D}=C_{D 0}+K C_{L}^{2}$

According to (15) and (15'), the drag is assumed with a reasonable precision as a quadratic function of lift.

The effect of compressibility can be predicted by the use of a correction factor for speeds ranging from $M=0.4$ up to transonic, but in this case it can be not considered.

The lift dependant component can be approximated as

$K=\frac{1}{\pi \cdot A_{x, y} R \cdot e}$

where $e$ is the efficiency factor of planform wing. It is indicated in Appendix 1 for the specific kind of aircraft.

In case of takeoff and landing, drag can be evaluated by considering that the landing gears are fully extended, increase the $\mathrm{C}_{\mathrm{D} 0}$ and there is a reduction in the induced drag due to the close proximity of the wings to the ground. The following expression is used to calculate the increase in $\mathrm{C}_{\mathrm{D} 0}$ :

$\Delta C_{D, 0}=\frac{W}{S} K_{u c} m^{-0.215}$

and the drag is consequently ( $\left.8^{\prime \prime}\right)$

$C_{D, 0}+\Delta C_{D, 0}=C_{D, 0}+\frac{W}{S} K_{u c} m^{-0.215}$

where:

- $\quad W / S$ is the wing loading in unit of Newton per square meter intended primarily for use in incompressible flow conditions

- $\quad m$ is the maximum mass of the airplane in kilograms

- $K_{u c}$ is a factor that depends of the amount of flap deflection. For maximum flap deflection, $K_{u c}=3,1610^{-5}$.

\subsection{Flight mechanics}

\subsubsection{Flight analysis in a vertical plane}

The lift and drag are aerodynamic forces that are defined relative to the flight path. The lift is perpendicular to the flight path and the drag is along the flight path. The thrust of the aircraft is also usually aligned with the flight path. We initially 
Fig. 7 Forces on an aircraft

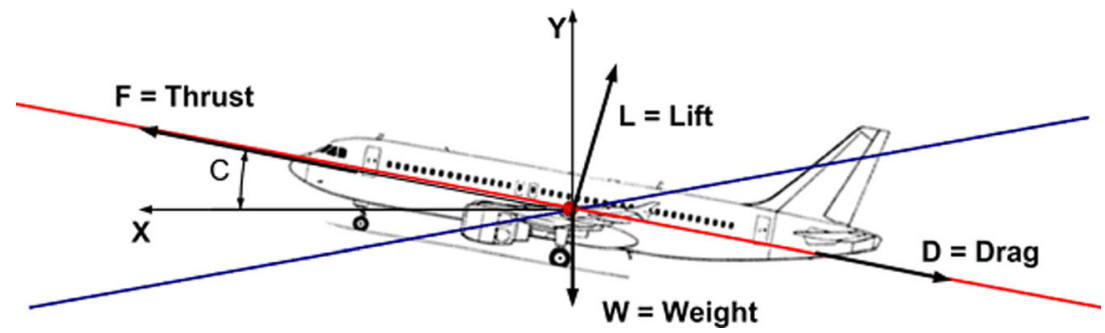

assume and investigate the ideal positioning of the ACHEON nozzle to take the max advantage during take off and landing operations, assuming that it changes the angle of the thrust only during take off and landing operations.

Elementary equations of flight become (Fig. 7):

$\sum_{i} F_{y, i}=m \cdot a_{y} \rightarrow T \cdot \sin c-D \cdot \sin c+L \cdot \cos c-W=m \cdot a_{y}$
$\sum_{i} F_{x, i}=m \cdot a_{x} \rightarrow T \cdot \cos c-D \cdot \cos c+L \cdot \sin c=m \cdot a_{x}$

where lift is

$L=0.5 \cdot C_{L} \cdot \rho_{\text {air }} \cdot u^{2} \cdot A_{x, y}$

and drag is

$D=0.5 \cdot C_{D} \cdot \rho_{\text {air }} \cdot u^{2} \cdot A_{y, z} \cdot$

The resulting equations of motion are:

$\left\{\begin{array}{l}(T-D) \cdot \cos \gamma-L \cdot \sin \gamma=m \cdot a_{x} \\ (T-D) \cdot \sin \gamma+L \cdot \cos \gamma-W=m \cdot a_{y}\end{array}\right.$

For small climb angles $\left(<6^{\circ}\right)$, the $\cos \gamma$ is nearly 1 and the $\sin (\gamma)$ is nearly zero. The system of Eq. (1') then reduces to

$\left\{\begin{array}{l}(T-D) \cong m \cdot a_{x} \\ L \cdot \cos \gamma-W=m \cdot a_{y}\end{array}\right.$

Assuming that thrust can assume different angles than the trajectory of motion (Fig. 8), the angle of the variable thrust respect the trajectory is defined with $t$. The thrust can be expressed as a function of the angle $t+c$, which is the sum of the climbing angle with the angle of the thrust with the trajectory:

$\left\{\begin{array}{l}T_{x}-D \cdot \cos \gamma-L \cdot \sin \gamma=m \cdot a_{x} \\ T_{y}-D \cdot \sin \gamma+L \cdot \cos \gamma-W=m \cdot a_{y}\end{array}\right.$,

where $T_{x}$ and $T_{y}$ are expressed as follows:

$\left\{\begin{array}{l}T_{x}=T \cdot \cos (\gamma+t) \\ T_{y}=T \cdot \sin (\gamma+t)\end{array}\right.$.

The system of Eq. (23) can be expressed by assuming the internal trigonometric relations and becomes:

$\left\{\begin{array}{l}(T \cdot \cos t-D) \cdot \cos \gamma-(T \cdot \sin t+L) \cdot \sin \gamma=m \cdot a_{x, t} \\ (T \cdot \cos t-D) \cdot \sin \gamma+(T \cdot \sin t+L) \cdot \cos \gamma-W=m \cdot a_{y, t}\end{array}\right.$

As before, for small climb angles $\left(<6^{\circ}\right)$, the term $\cos (\mathrm{c})$ is nearly one and the term $\sin (\mathrm{c})$ is null. The system of Eq. (24) then reduces to Eq. (25):

$\left\{\begin{array}{l}T \cdot \cos t-D=m \cdot a_{x, t} \\ T \cdot \sin t+L-W=m \cdot a_{y, t}\end{array}\right.$

Showing clearly the contribution of the terms due to the variable direction thrust, which is positive, when thrust is directed upward, and negative, when thrust is directed downward the climbing trajectory.

\subsubsection{Stall analysis}

The calculated the stall speeds are respectively:

$u_{\text {stall }, t=0}=\sqrt{\frac{W}{0.5 \cdot C_{L \max } \cdot \rho_{\text {air }} \cdot A_{x, y}}}$

Fig. 8 Forces on an aircraft with variable thrust direction

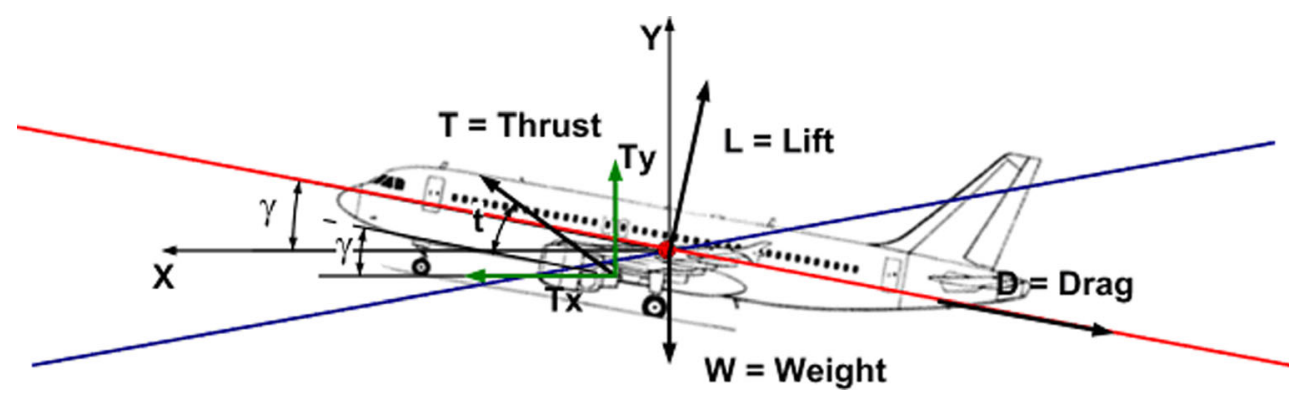




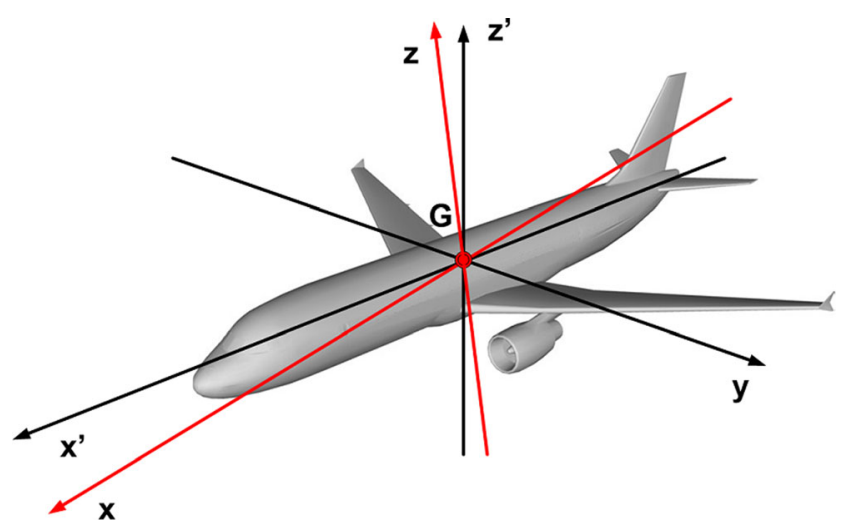

Fig. 9 Axis of an aircraft

$u_{\text {stall }}=u_{\text {stall }, t=0} \cdot \sqrt{1-\frac{T \cdot \sin t}{\mathrm{~W}}}$

It is evident that the stall speed with upward directed thrust is lower than the stall speed in a traditional airplane, higher when thrust is directed downward.

It can be obtained that $u_{\text {stall }}=0$ if

$1-\frac{T \cdot \sin t}{W}=0 \rightarrow \sin t=\frac{W}{T}$

\subsubsection{Stability analysis}

Stability analysis will allow the definition of the optimal positioning of the ACHEON propulsion to achieve different goals and satisfy different mission profiles. Stability analysis is fundamental for defining optimal aircraft architecture. In flight, any aircraft will rotate about its center of gravity, a point, which is the average location of the mass of the aircraft. We can define a three dimensional coordinate system through the center of gravity with each axis of this coordinate system perpendicular to the other two axes (Fig. 9).
In Fig. 9, two coordinate systems have been defined: $x, y, z$ (with $x$ parallel to the horizontal and $z$ vertical), $x^{\prime}, y, z^{\prime}$ (with $x^{\prime}$ parallel to the trajectory and $z^{\prime}$ axis orthogonal to the trajectory) and $x^{\prime \prime}, y, z^{\prime \prime}$ with ( $x^{\prime \prime}$ parallel to the aircraft fuselage axis and $z^{\prime \prime}$ perpendicular to this axis). The angle $\alpha$ is the angle of attach that the fuselage forms with the trajectory. The orientation of the aircraft by the amount of rotation of the $x^{\prime \prime}, y, z^{\prime \prime}$ coordinate system on $x, y, z$ in the point $\mathrm{G}$.

\subsubsection{Pitch motion}

The pitch axis is the $y$ axis, perpendicular to the aircraft centreline and lies in the plane of the wings. Pitch motion is an up or down rotation around the centre of gravity.

The pitching motion is being caused by the deflection of the elevator of the aircraft. but also influenced by position where thrust is applied.

The pitch equilibrium is presented in Fig. 10.

The equilibrium of torques of the aircraft is calculated around one of the significant points. Usually it is defined as the center of aerodynamic forces, but in this case due to its variation as a function of different parameters such as speed it is preferred to define the centre of mass as being nearly constant.

It can be demonstrated that the case when the thrust application point is almost coincident with the centre of gravity the action of the thrust direction change is neutral in terms of effects on the pitch. It can be also easily demonstrated that, if it is not coincident, the directional change of the thrust can be used instead of ailerons for stabilizing the aircraft.

\subsubsection{Roll motion}

In flight, any aircraft will rotate about its center of gravity. The roll axis lies along the aircraft centreline. The deflection of the

Fig. 10 Pitch rotation equilibrium

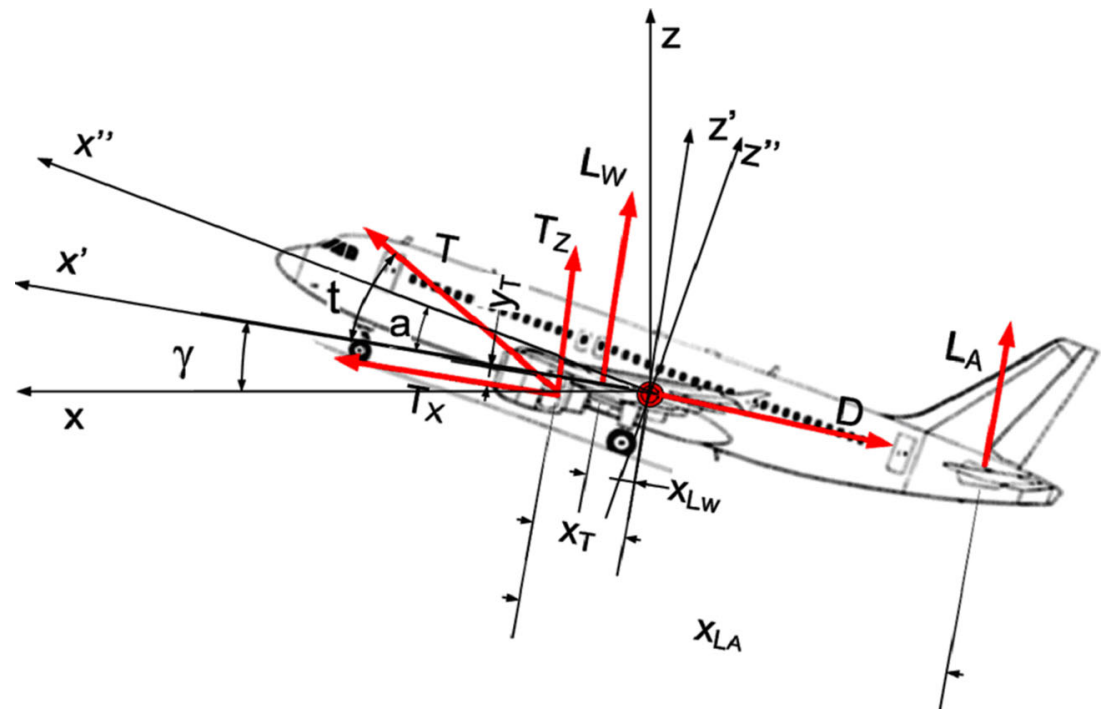


Fig. 11 Roll rotation with upward directed thrust

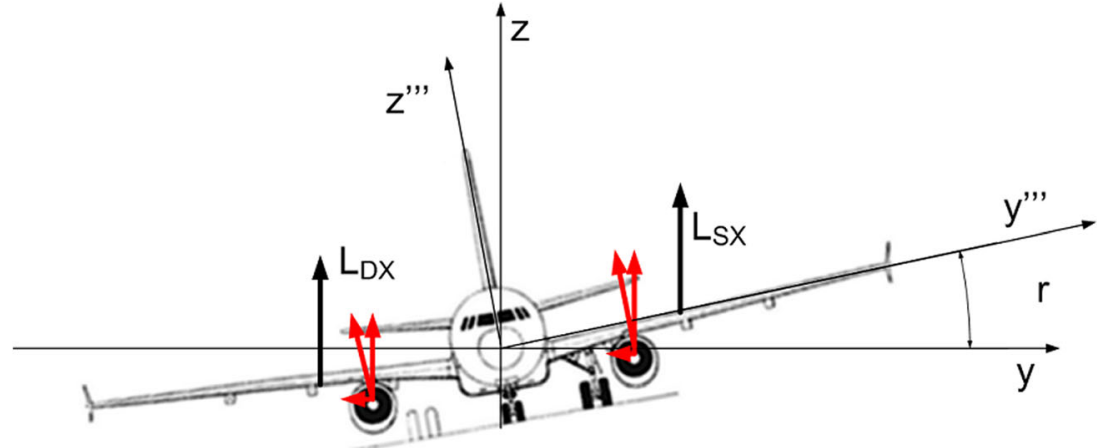

ailerons of the aircraft causes the rolling motion. The aileron is a hinged section at the rear of each wing. The ailerons work in opposition; when the right aileron goes up, the left aileron goes down.

Changing the angle of deflection at the rear of an airfoil will change the amount of lift generated by the foil. With greater downward deflection, the lift will increase in the upward direction; with greater upward deflection, the lift will decrease in the upward direction. Since the ailerons work in pairs, the lift on one wing increases as the lift on the opposite wing decreases. Because the forces are not equal, there is a net twist, or torque about the center of gravity and the aircraft rotates about the roll axis. The pilot can use this ability to bank the aircraft, which, causes the airplane to turn. it is clear that, if variable direction propulsion, such as ACHEON, are installed, benefits could immediately arise on the roll motion control assuming that the distance of the propeller could be long enough.

Figures 11 and 12 shows the roll rotation with upward directed thrust and Fig. 8 with downward directed thrust. Both configurations can be achieved during different flight operations.

\subsection{Pull up and push over manoeuvres}

Considering at this level only manoeuvres on the vertical plane, two types of flight manoeuvres are a symmetric: pull up and push over. In either case further terms are added to define the dynamic equilibrium of flight.

For a symmetric pitch up, we conventionally assume that the vehicle is moving in a large vertical circle, even if the trajectory can present some differences. When the manoeuvre starts, the forces, in an airplane with thrust aligned with the $\mathrm{x}$ axis in the vertical direction are:

$L(u)-W=m \cdot \frac{V^{2}}{R}=\frac{W}{g} \cdot \frac{V^{2}}{R}$

The forces in horizontal direction are:

$T-D(u)=m \cdot a_{c}=\frac{W}{g} \cdot a_{c}$

In the case of an inclined thrust, the equilibrium of the forces is:

$L(u)+T \cdot \sin t-W=m \cdot \frac{u^{2}}{R}=\frac{W}{g} \cdot \frac{u^{2}}{R}$

and

$T \cdot \cos t-D(u)=m \cdot a_{c}=\frac{W}{g} \cdot a_{c}$

It is the clear that by deflection of the thrust lower pitch up radius can be assumed with upward directed thrust and higher with downward directed thrust.

Fig. 12 Roll rotation with downward directed thrust

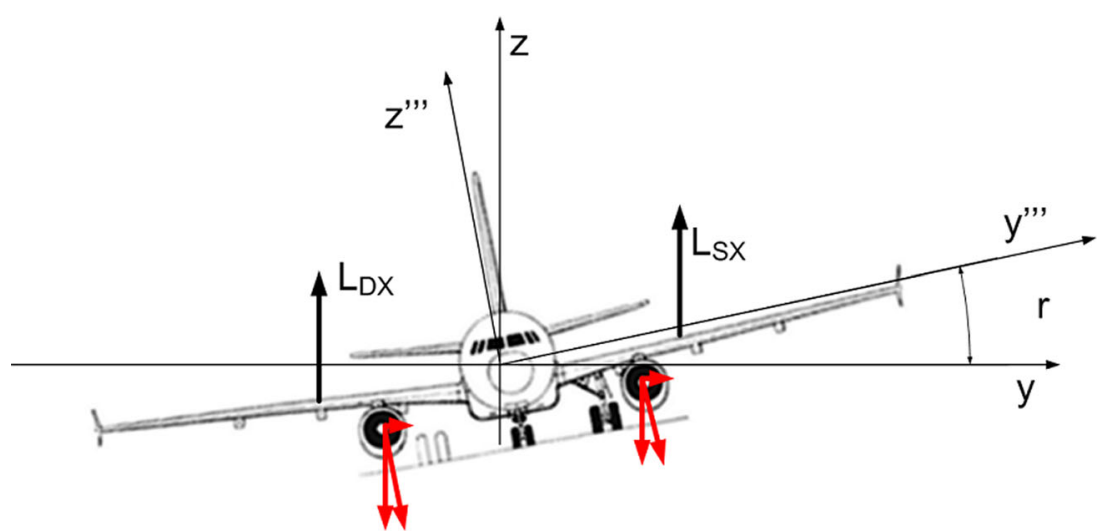




\subsection{Take off and landing operations}

\subsubsection{Takeoff run dynamics}

Figure 13 represents take off operation with a directional thrust.

A well working set of equation that allows modelling takeoff operations is provided by Phase [25]. It is also necessary to consider in this part the Federal Aviation Regulations that defines acceptable procedures for take off operations, FAR $25.103,105,107,109,111,113$ [35-40].. If thrust is horizontal and the weight $W=m g$ the equations of takeoff run are:

$\frac{W}{g} \cdot \frac{d u}{d \tau}=T-D(u)-\mu \cdot[W-L(u)]=T-R_{t=0}(u)$

where

$R_{t=0}(u)=D(u)-\mu \cdot[W-L(u)]$

and

$W \geq L(u)$,

If the thrust is directed in a direction, which is different from the horizontal, it can be obtained:

$\frac{W}{g} \cdot \frac{d u}{d \tau}=T \cdot \cos t-D-\mu \cdot(W-L-T \sin t)$,

which becomes

$\frac{W}{g} \cdot \frac{d u}{d \tau}=T \cdot \cos t-D(u)-\mu \cdot[W-L(u)]=T-R(u)$,

where

$R(u)=R_{t=0}(u)-\mu \cdot T \cdot \sin t$,

and

$W=m g \geq L(u)+T \cdot \sin t$

Fig. 13 Forces during takeoff run
The equal condition in Eq. (39) is satisfied at the takeoff point.

The take off condition results:

$W=L\left(u_{\text {takeoff }}\right)+T \cdot \sin t$.

the equilibrium in vertical direction expressed by Eq. (38) results

$W=0.5 \cdot C_{L} \cdot \rho_{\text {air }} \cdot u_{\text {takeoff }}^{2} \cdot A_{x, y}+T \cdot \sin t$,

that allows calculating the take off speed, which results in the case of $t=0$,

$u_{\text {takeoff }, t=0}=\sqrt{\frac{W}{0.5 \cdot C_{L} \cdot \rho_{\text {air }} \cdot A_{x, y}}}$

and in the case of directional thrust it becomes

$u_{\text {takeoff }}=u_{\text {takeoff }, t=0} \cdot \sqrt{1-\frac{T \cdot \sin t}{\mathrm{~W}}}$.

Equation (43) demonstrates clearly that the take off speed is lower than the one with $t=0$ in the case that $t>0$, or thrust is oriented upward, and higher in the case that thrust is oriented downward.

Usually the takeoff speed is higher than stall speed at ground level. It is usually assumed that:

$1.1 \cdot u_{\text {stall }}=u_{\text {takeoff }}=1.2 \cdot u_{\text {stall }}$

it can be then verified that

$1.1 \sqrt{\frac{1}{C_{L_{\max }}}}<\sqrt{\frac{1}{C_{L}}}<1.2 \sqrt{\frac{1}{C_{L}}}$

which gives

$\frac{25}{36} C_{L \max }<C_{L}<\frac{100}{121} C_{L \max }$.

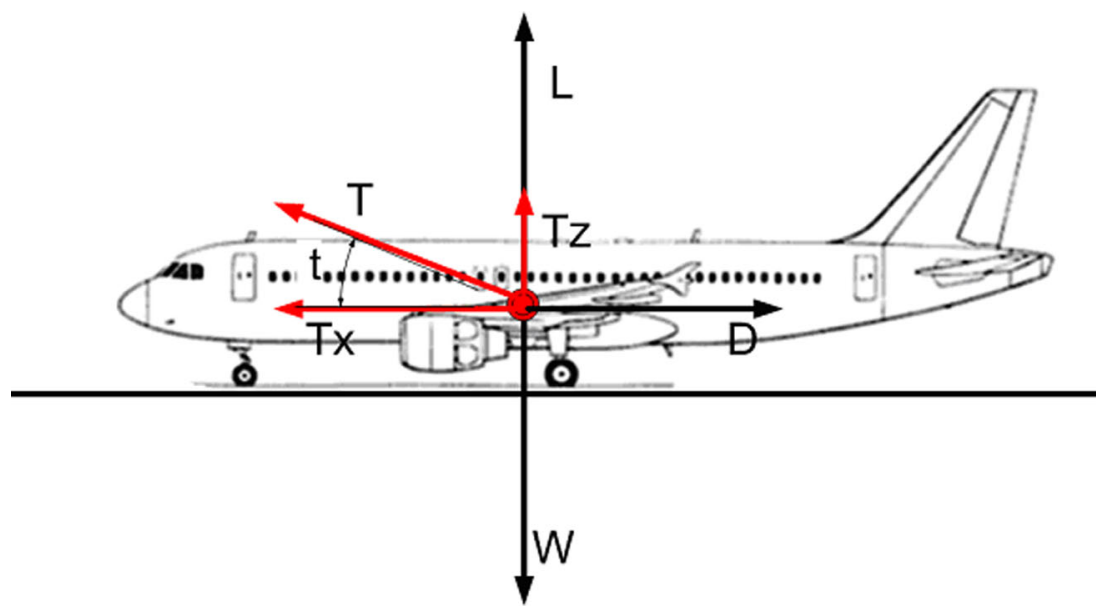


An effective analysis of the detachment phase can be performed after the analysis of the ground-based run after take off.

\subsubsection{Detachment from the ground}

After the preliminary ground run the most critical phase of the plane behaviour is the detachment phase, which is regulated by FAR standards (Fig. 14). Take off is concluded only when an airplane has reached an height of $10 \mathrm{~m}$. Assuming the hypothesis that during this phase the velocity does not change significantly and remains almost constant .

The radius of curvature can be calculated by Eqs. (33) and (34). In the case of assuming $u_{\text {takeoff }}$ constant, they becomes respectively:

$R_{t=0}=\left(L\left(u_{\text {takeoff }, t=0}\right)-W\right) \cdot \frac{g}{W \cdot u_{\text {takeoff }, t=0}^{2}}$

$R=\left(L\left(u_{\text {takeoff }}\right)+T \cdot \sin t-W\right) \cdot \frac{g}{W \cdot u_{\text {takeoff }}^{2}}$

it can be demonstrated that the most interesting condition is

$\frac{R}{R_{t=0}} \leq 0 \rightarrow \frac{\left(L\left(u_{\text {takeoff }}\right)+T \cdot \sin t-W\right)}{\left(L\left(u_{\text {takeoff }, t=0}\right)-W\right)} \cdot \frac{u_{\text {takeoff }, t=0}^{2}}{u_{\text {takeoff }}^{2}} \leq 0$

After this operation, the motion continues with a climb.

\subsubsection{Landing operations}

Landing operations can be modelled in a similar way and are almost symmetrical (Fig. 15). In this case FAR 25.119 Landing climb all engines [41], and FAR 25.125 - Landing [42] applies. Landing operations can be described assuming an initial push over manoeuvre, which starts at cruise speed $u_{\text {cruise }}$ and can be modelled in both cases respectively:

$$
\begin{aligned}
& R_{t=0}=\left(-L\left(u_{\text {cruise }, t=0}\right)+W\right) \cdot \frac{g}{W \cdot u_{\text {cruise }, t=0}^{2}} \\
& R=\left(-L\left(u_{\text {cruise }}\right)-T \cdot \sin t+W\right) \cdot \frac{g}{W \cdot u_{\text {cruise }}^{2}}
\end{aligned}
$$

In the case of Eq. (49) with directional thrust, it is evident that the same radius can be obtained in two modes: a low lift configuration with higher vertical thrust component, or a higher lift configuration and lower vertical thrust component, but also with a downward directed thrust, without changing the aircraft configuration.

The following manoeuvre is the climb down, with deceleration to a velocity, which is about touch down speed $u_{\text {landing. }}$ It is in the range

$$
1.2 \cdot u_{\text {stall }}=u_{\text {landing }}=1.3 \cdot u_{\text {stall }} \text {. }
$$

Usually a value of $1.23 \mathrm{u}_{\text {stall }}$ is adopted.

$$
u_{\text {land }}=u_{\text {land }, t=0} \cdot \sqrt{1-\frac{T \cdot \sin t}{\mathrm{~W}}} .
$$

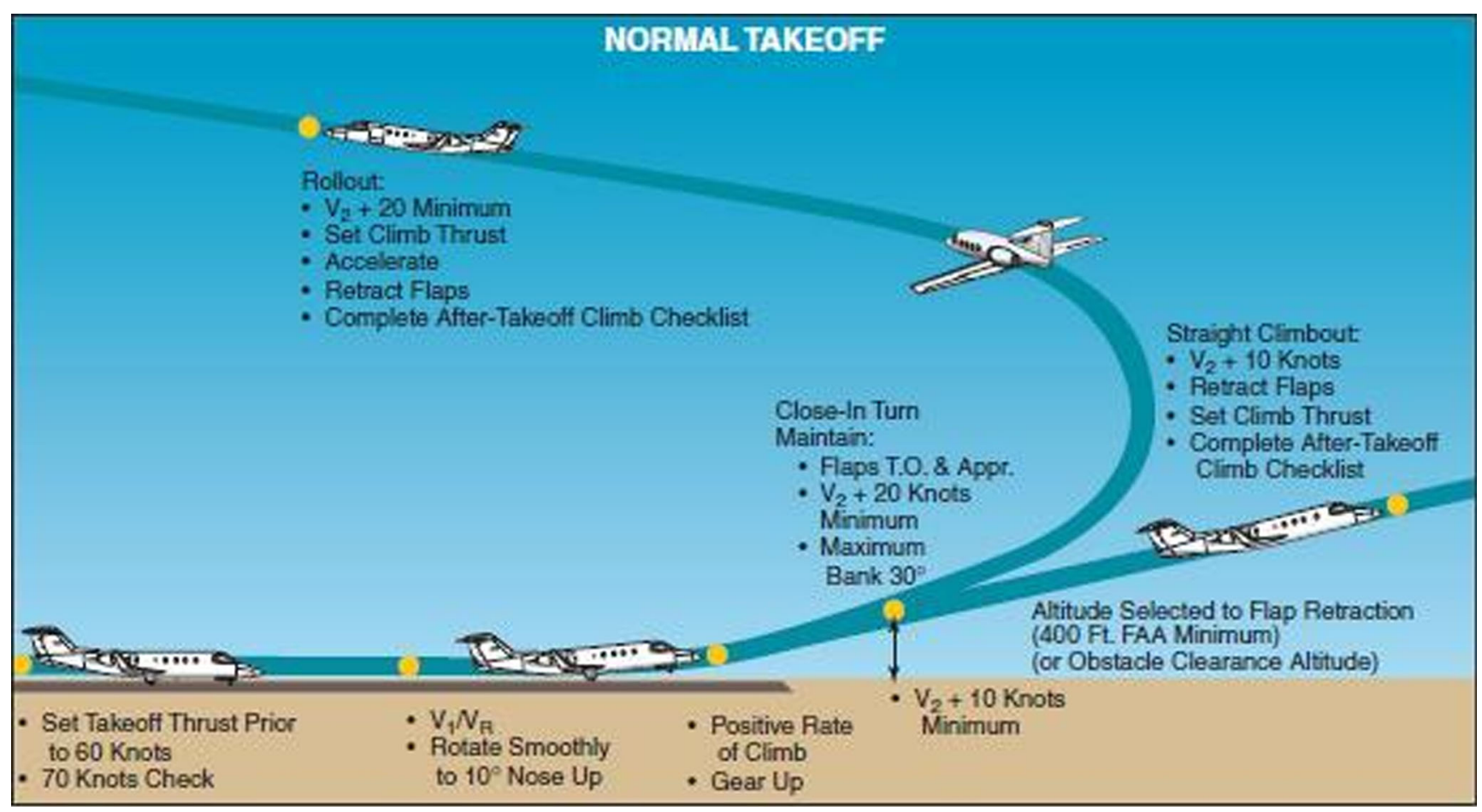

Fig. 14 Takeoff profile and critical velocities identified by FAR 


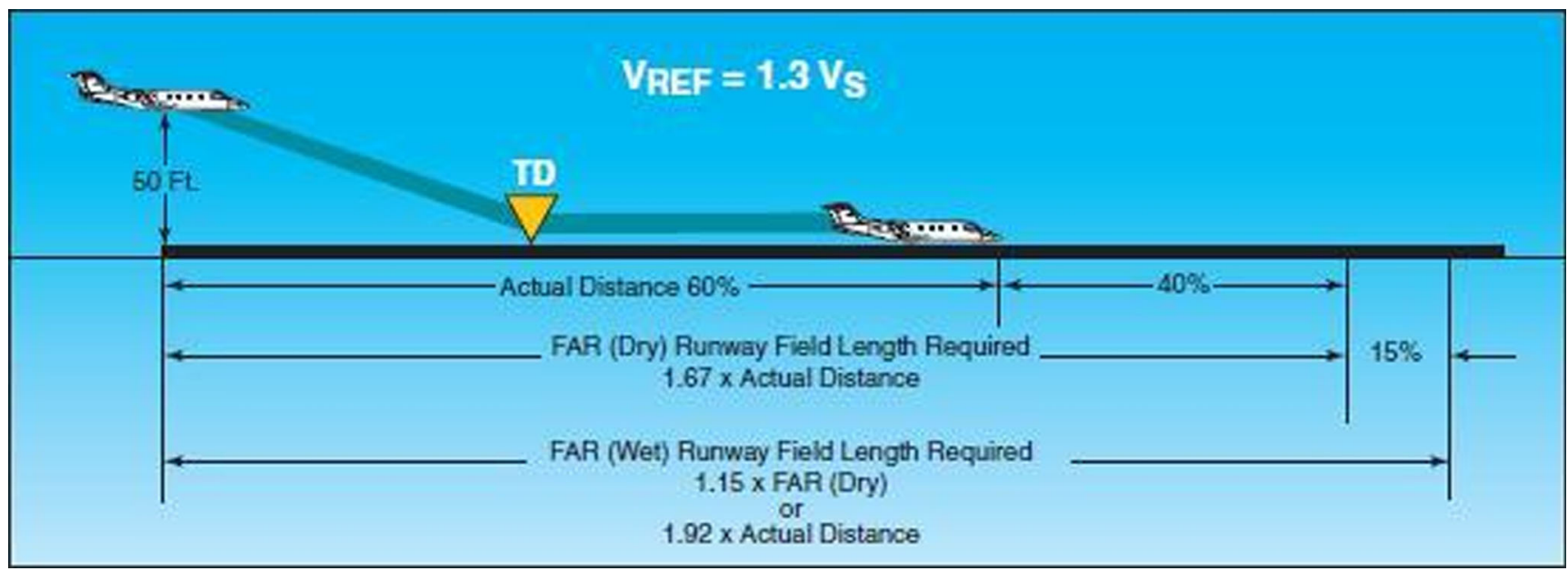

Fig. 15 Landing profile and critical velocity as identified by FAR

In this case, a much lower landing horizontal speed can be ensured:

$-0.5 \cdot C_{D} \cdot \rho_{\text {air }} \cdot u_{\text {down }}^{2} \cdot A_{y, z}-T \cdot \cos t-w \cos \gamma$

where $\gamma$ is the climbing angle.

In particular, it assumes vertical configuration when

$m \cdot a_{y}=-W+0.5 \cdot C_{D} \cdot \rho_{\text {air }} \cdot u_{\text {down }, y}^{2} \cdot A_{x, y}-T \cdot \sin t$

$-0.5 \cdot C_{D} \cdot \rho_{\text {air }} \cdot u_{\text {down }, x}^{2} \cdot A_{y, z}-T \cdot \cos t$

The final manoeuvre before touching the ground is a further rotation with centre higher than the trajectory starting at $50 \mathrm{ft}(15.24 \mathrm{~m})$ with radius:

$R_{t=0}=\left(L\left(u_{\text {land }, t=0}\right)-W\right) \cdot \frac{g}{W \cdot u_{\text {land }, t=0}^{2}}$

$R=\left(L\left(u_{\text {land }}\right)+T \cdot \sin t-W\right) \cdot \frac{g}{W \cdot u_{\text {land }}^{2}}$

In addition, in this case operations could be performed by different combinations of vertical thrust and lift force, including fixed aerodynamic configurations governed simply by jet.
It can be then possible to model the final part. If the thrust is directed in horizontal direction or in a direction, which is different from the horizontal, it can be obtained:

$\frac{W}{g} \cdot \frac{d u}{d \tau}=T \cos t-D-\mu_{\text {brake }} \cdot(W-L+T \sin t)$,

where $\mu_{\text {brake }}$ is the friction coefficient during braking phase.

In this case, some thrust directed vertically can be interesting. Braking space can be easily evaluated as in the case of the takeoff run.

\subsection{Aircraft configuration}

The aircraft configuration has been studied subject to the aircraft performance and required power for different operations. A complete analysis of the performances of the modified Cessna 402 plane will be performed against the traditional plane with propellers [43]. In particular, Fig. 16 shows the airplane configuration with a section on the ACHEON propeller illustrating the main positioning of the system.

Figure 17 shows the detail of the ACHEON nozzle section and its configuration so to allow a better comprehension of its behaviour. In particular, the proposed model presents a limitation in angular terms of the jet, to allow an effective prediction of the maximum angle, which could be reached.

Fig. 16 ACHEON configuration on a longitudinal plane section and main directions of thrust

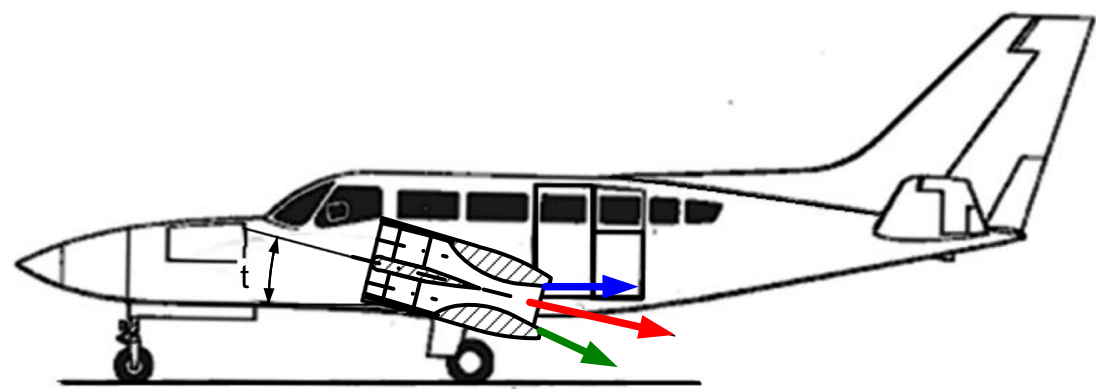


Fig. 17 Nozzle positioning and limiting thrust vector directions

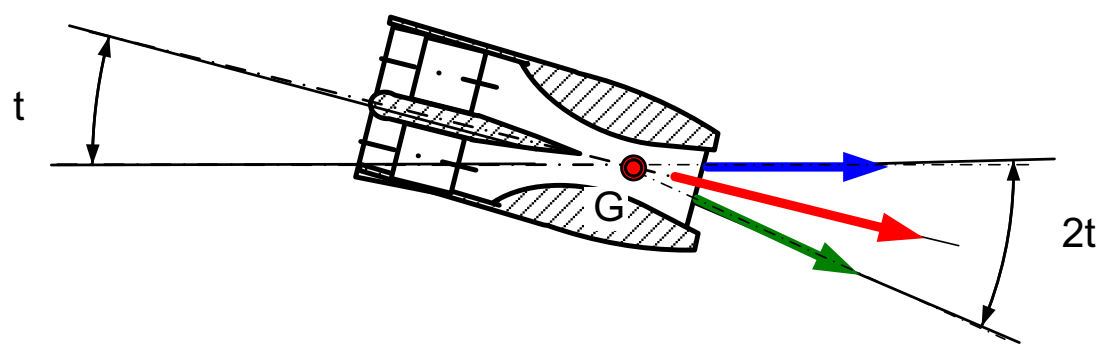

To simplify the model controls and to ensure a better integration with the airplane configuration a positioning of the geometric centre of thrust coincident with the centre of gravity will be considered. Otherwise, it is evident that torque components could be introduced with negative consequences on the aircraft behaviour. The application of the centre of thrust rotation in the centre of gravity could is also considered to increase the safety of the system and allowing an adequate system behaviour in case of technical problems.

In particular, there will be assumed three limiting positions:

- $\quad$ an angle $=0$ ensured by top jet (horizontal flight);

- $\quad$ an angle $=t$ ensured by both jets (take off);

- an angle $=2 t$ ensured by bottom jet (landing).

Different angles $t$ could apply, as demonstrated by the project activities. they space in a range $12 \div 25^{\circ}$. The effects will be evaluated for some specific angles, while jet velocity and regimes will be defined according to specific conditions.

Energetic and environmental evaluations will be also performed.

\subsection{Mission profile}

To describe the results a specific mission will be considered. The typical mission profile is defined according to the FAR standards for commercial vehicles.

In some operations, different operative methods will be taken into account and will be compared. The analysis will also consider FAR standards to verify the suitability of the system for future application into aviation. Further considerations will regard the possible modifications, which could be necessary to the FAR to allow ACHEON integration. ACHEON will be also preliminarily evaluated against EC Reg. No. 216/2008 [25], identifying future certification needs for flying in Europe. A typical mission profile is illustrated in Fig. 18.

\section{Results}

The results will be compared to the effective performance of a Cessna 402 identifying improved and degraded operation. Energy and performance related considerations would be performed focusing on the specific effects of the all-electric ACHEON propulsion system.

Further consideration will regard the necessity of further improvements, which could be necessary for implementing in ACHEON. It is assumed to use the same aerodynamic configuration, which is used for the traditional version and equal thrust condition.

The main parameters of the aircraft have been preliminarily calculated $[27-30,44]$. The propulsion model is shown in Fig. 19. The lift and drag data are calculated and reported in Table 2 and the engine data in Annex, will be used as models of the aircraft and engine.

A concrete/asphalt runoff is assumed with a friction coefficient 0.02 for takeoff and landing operations.

\subsection{Take off evaluation}

The following data can be assumed by FAR Part 25 (Table 3).

Simplified takeoff profile is assumed Main data have been reported in Tables 4 and 5.
Fig. 18 Typical mission profile divided in mission and reserves

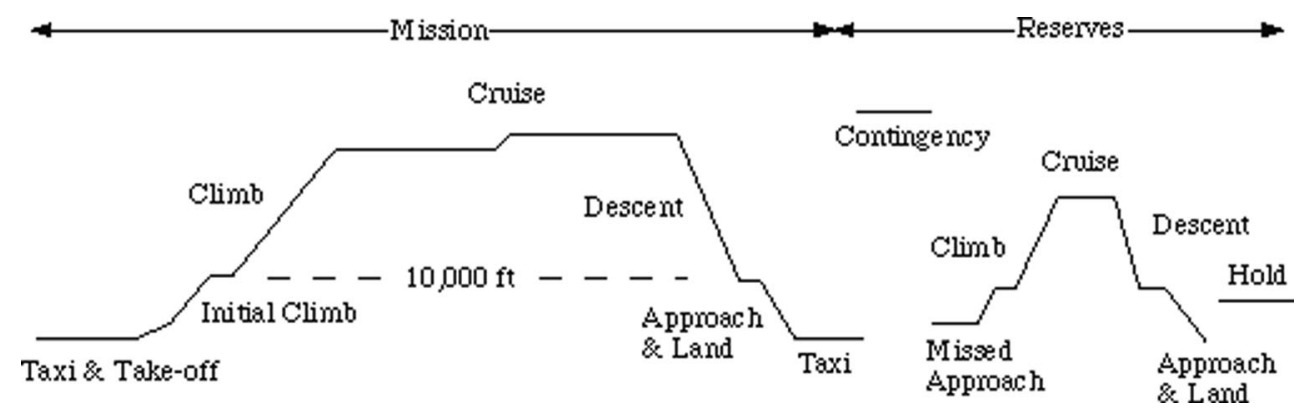




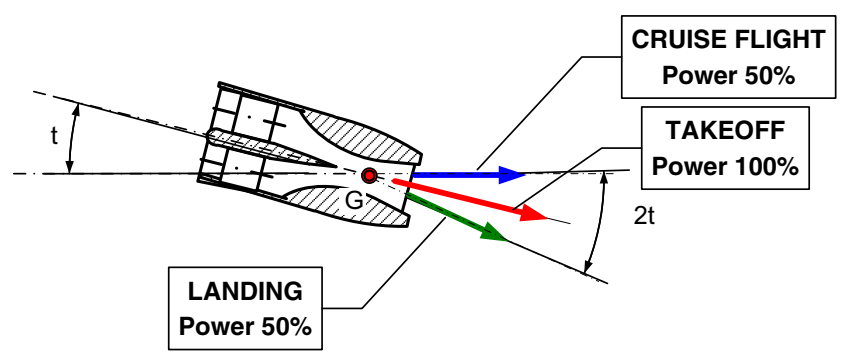

Fig. 19 Preferential use of different configurations during different flight operations

The values in Table 6 have been calculated during takeoff, considering that the average speeds during these operations has been evaluated at $0.71 u_{\text {takeoff }}$ [45]. It is the first part of the takeoff it relates to the following phases transition a screen up to $35 \mathrm{ft}(10 \mathrm{~m})$ has been considered, as specified by FAR Part 25. Maximum initial vertical speed of $7.6 \mathrm{~m} / \mathrm{s}$ is assumed for the CESSNA 402 and it results after take off. It means that the initial average horizontal speed is $52.7 \mathrm{~m}$.

Energy requirements for take off includes also taxi time, wait and run, according to FAR Part 25. Ten minutes operation time has been estimated. .

Advantages in terms of energy saving are evident at each angle of the takeoff length. It can be verified that if a well defined load factor has been assumed during operations that could not exceed 1 , adequate comfort of the passengers is ensured,

$n=L / W$,

which becomes for ACHEON propelled airplanes

$n=(L+T \sin t) / W \leq 1$,

that constitutes a precise limit to aerodynamic loading in function of the thrust.

$L \leq W-T \sin t$

Table 3 FAR Part 25 optimal takeoff and landing parameters

\begin{tabular}{llll}
\hline Flight Condition: & \multicolumn{2}{l}{ Number of Engines } \\
\cline { 2 - 4 } & 4 & 3 & 2 \\
\hline First Take-Off Segment & $0.5 \%$ & $0.3 \%$ & $0.0 \%$ \\
Second Take-Off Segment & $3.0 \%$ & $2.7 \%$ & $2.4 \%$ \\
Final Take-Off Segment & $1.7 \%$ & $1.5 \%$ & $1.2 \%$ \\
Enroute Climb & $1.6 \%$ & $1.4 \%$ & $1.1 \%$ \\
Approach Segment & $2.7 \%$ & $2.4 \%$ & $2.1 \%$ \\
Landing Segment & $3.2 \%$ & $3.2 \%$ & $3.2 \%$ \\
\hline
\end{tabular}

It shows clearly that the flight assist can be ensured in two ways:

1. by changing lift maintaining directional thrust;

2. by changing thrust direction maintaining aerodynamic lift.

The other evident result is that the same take off performance could be also obtained with a much-reduced aerodynamic lift and then a lower drag.

\subsection{Climb}

It is assumed that the plane at the end of takeoff segments up to $10,000 \mathrm{ft}(3048 \mathrm{~m})$ reaches the cruise speed $(109 \mathrm{~m} / \mathrm{s})$.

After the transition phase there is a slow transition from the dual jet configuration to allow the jet to adhere to the upper surface, as shown in Fig. 19, but also a climb with inclined Thrust can be performed. An angle of attach of 7 has been considered.

The difference in terms of accelerations between the two solutions is evident by subtracting the system of Eqs. (13) and (15).

$\left\{m \cdot\left(a_{x, t}-a_{x}\right)=T \cdot \cos t \cdot \cos c-T \cdot \sin t \cdot \sin c-T \cdot \cos c=T \cdot \cos (c+t)-T \cdot \cos c<0\right.$ $m \cdot\left(a_{y, t}-a_{y}\right)=T \cdot \cos t \cdot \sin c+T \cdot \sin t \cdot \cos c-T \cdot \sin c=T \cdot \sin (c+t)-T \cdot \sin c>0$

It is clear the difference of accelerations along $\mathrm{x}$-axis is reduced, while the one along $y$-axis is increased.

Average speed during climb can be evaluated in different configurations:

An average climb rate of $6.7 \mathrm{~m} / \mathrm{s}$ has been assumed. About $40 \mathrm{kWh}(144000 \mathrm{~kJ})$ are necessary in all the configurations. Expected energy consumption is about $140 \mathrm{kWh}(504000 \mathrm{~kJ})$ for traditionally propelled aircraft and about $53 \mathrm{kWh}$ $(191000 \mathrm{~kJ})$ for electric ones.

\subsection{Horizontal Flight}

Flight will is estimated considering the above model and standard atmospheric data at $1000 \mathrm{~m}$. An average angle of attachment of $3^{\circ}$ has been assumed, even if a twin engine aircraft in cruise could also fly with horizontal axis. Consumption for $1 \mathrm{~h}$ flight at $1000 \mathrm{~m}$ and cruise velocity is expected to be 1060 $k W h(3816000 \mathrm{~kJ})$ for traditional propulsion and about 360 $k W h(1296000 \mathrm{~kJ})$ for the electrical one only because of increased efficiency of electric propulsion. In the case of horizontal flight electric propelled airplane there is no mass reduction and this aspect must be considered during landing operations. 
Table 4 Flight behaviour

\begin{tabular}{llllll}
\hline & Angle of Attack & Angle of Climb & Pitch Attitude & Incidence & Airspeed \\
\hline Initial roll & $4.5^{\circ}$ & $0^{\circ}$ & $0.0^{\circ}$ & $4.5^{\circ}$ & Small, incr. \\
After rotation & $12.0^{\circ}$ & $0^{\circ}$ & $7.5^{\circ}$ & $4.5^{\circ}$ & increasing \\
At liftoff & $12.0^{\circ}$ & $0^{\circ}$ & $7.5^{\circ}$ & $4.5^{\circ}$ & $6 \%$ below $V_{\mathrm{Y}}$ \\
Initial climb & Decr. & incr. & $7.5^{\circ}$ & $4.5^{\circ}$ & increasing \\
Steady climb & $7.0^{\circ}$ & $5^{\circ}$ & $7.5^{\circ}$ & $4.5^{\circ}$ & $10 \%$ above $V$ \\
\hline
\end{tabular}

\subsection{Landing}

Landing energy needs can be evaluated according to usual twin-engine general aviation aircraft. Typical angle and airspeed during landing are presented in Table 6.

Landing modes have been presented in Fig. 20 assuming a traditional $3^{\circ}$ glideslope. Figure 20 shows instead the complete landing manoeuvre considered. It is clear that gliding takeoff requires low energy consumption. A $3^{\circ}$ degree glideslope for a traditional Cessna 402 will require a landing space, which can be calculated and against the value of $757 \mathrm{~m}$ (declared by the producer). Calculations give a worst result of about $763 \mathrm{~m}$, which is acceptable because of the necessary approximations in calculations.

Data between the descent phase and landing using ACHEON can be assumed adopting a different profile (Table 7).

Different profiles of climbing have been considered for ACHEON propelled aircraft. They can be ensured by hybrid combination of vertical component of the thrust, when adhering to the lower surface and aerodynamic lift. In this case the thrust in vertical direction could be almost equal to the one during takeoff, while the horizontal one is much reduced. Angle of attack is considered the same as above. Considering different stall speeds and maximum deceleration about $3 \mathrm{~m} / \mathrm{s}$ both spaces and times for landing operations have been calculated. Results are presented in Table 8 .

It is now evident that ACHEON can also perform better performances in case of landing.

\subsection{Further ACHEON system improvements}

The ACHEON propulsion system can be improved by optimizing the inlet by an effective improvement of the inlet section, as verified by Trancossi and Madonia [46]. By optimizing the air intake design it can be possible to increase the propulsive efficiency especially at high altitude. But this level of optimization it is not performed at this level because it requires a more effective design activity.
Table 5 Takeoff comparison between tradional Cessna 402 and Cessna 402 with ACHEON with different angles of inclination

\begin{tabular}{|c|c|c|c|c|c|c|c|c|c|}
\hline \multirow{3}{*}{$\begin{array}{l}\text { Angle of deflection } \\
\text { Direction of }\end{array}$} & \multirow[t]{3}{*}{ Propellers } & \multicolumn{7}{|c|}{ ACHEON } & \multirow[b]{3}{*}{$\mathrm{Kg}$} \\
\hline & & \multicolumn{2}{|l|}{$15^{\circ}$} & \multicolumn{2}{|l|}{$10^{\circ}$} & \multicolumn{2}{|l|}{$5^{\circ}$} & \multirow{2}{*}{$\begin{array}{l}0^{\circ} \\
\mathrm{Tx}\end{array}$} & \\
\hline & & $\mathrm{Tx}$ & Ty & $\mathrm{Tx}$ & Ty & $\mathrm{Tx}$ & Ty & & \\
\hline Thrust & 5185.2 & 5009 & 1342 & 5106 & 900.4 & 5166 & 451.9 & 5185 & $\mathrm{~kW}$ \\
\hline Max Power & 280 & 280 & & & & & & & $\mathrm{~m} / \mathrm{s}$ \\
\hline $\mathrm{u}_{\text {stall }}$ & 46.3 & 26.3 & & 32.9 & & 39.5 & & 46.3 & $\mathrm{~m} / \mathrm{s}$ \\
\hline $\mathrm{u}_{\text {stall,carriage, down }}$ & 31.74 & 18 & & 22.6 & & 27.1 & & 31.7 & $\mathrm{Kg}$ \\
\hline Take off mass & 3105 & 3105 & & & & & & & $\mathrm{~m} / \mathrm{s}$ \\
\hline Lift Off Speed & 50.93 & 28.93 & & 36.19 & & 43.45 & & 50.93 & $\mathrm{~m} / \mathrm{s}$ \\
\hline Take off Speed & 55.56 & 31.56 & & 39.48 & & 47.4 & & 55.56 & $\mathrm{~m}$ \\
\hline Liftoff Length & 641.5 & 206.8 & & 323.4 & & 468.4 & & 690 & $\mathrm{~m}$ \\
\hline $\begin{array}{l}\text { Takeoff Length } \\
\text { (calculated) }\end{array}$ & 690 & 222.4 & & 347.8 & & 503.8 & & 690 & $\mathrm{~m}$ \\
\hline Take off length declared & 670 & & & & & & & & $\mathrm{~m} / \mathrm{s}$ \\
\hline Lift Off Time & 16.5 & 9.48 & & 11.9 & & 14.32 & & 16.5 & $\mathrm{~S}$ \\
\hline Take Off Time & 17.74 & 10.2 & & 12.8 & & 15.4 & & 17.74 & $\mathrm{~kJ}$ \\
\hline Energy needs & 132012 & 27468 & & 31068 & & 34668 & & 44280 & $\mathrm{~kJ}$ \\
\hline Energy saving & 0 & 104544 & & 100944 & & 97344 & & 87732 & - \\
\hline Energy saving & 0 & $79.19 \%$ & & $76.47 \%$ & & $73.74 \%$ & & $66.46 \%$ & \\
\hline
\end{tabular}


Table 6 Landing parameters according to FAR25

\begin{tabular}{llllll}
\hline & Airspeed (KCAS) & Pitch Attitude & Incidence & Angle of Climb & Angle of Attack \\
\hline Cruise (clean) & $100 \div 120$ & $0.0^{\circ}$ & $4.5^{\circ}$ & $0.0^{\circ}$ & $4.5^{\circ}$ \\
Level VY (clean) & 70 & $4.0^{\circ}$ & $4.5^{\circ}$ & $0.0^{\circ}$ & $8.5^{\circ}$ \\
Level (flaps) & 70 & $0.0^{\circ}$ & $8.5^{\circ}$ & $0.0^{\circ}$ & $8.5^{\circ}$ \\
Slower (flaps) & 65 & $2.0^{\circ}$ & $8.5^{\circ}$ & $0.0^{\circ}$ & $10.5^{\circ}$ \\
Descent (flaps) & 65 & $-2.0^{\circ}$ & $8.5^{\circ}$ & $-4.0^{\circ} \div-6.0^{\circ}$ & $10.5^{\circ}$ \\
Flare (flaps) & decr. & incr. & $8.5^{\circ}$ & incr. & incr. \\
Stall (flaps) & 46.3 & $12.0^{\circ}$ & $8.5^{\circ}$ & $0.0^{\circ}$ & $20.5^{\circ}$ \\
\hline
\end{tabular}

\subsection{Energy analysis}

This analysis focuses on the energy analysis of the electrical ACHEON propelled Cessna 402 against the model on the market $[47,48]$. This analysis produces some interesting results.

In particular, the energy comparison are presented in Table 9. An emergency reserve higher than $15 \%$ is assumed to ensure some minutes flight for the electric ACHEON Propelled aircraft then the time for flight at cruise condition could not exceed 20 min for electric ACHEON propelled plane.

It can be verified that the original configuration is not adequately performing in terms of autonomy and energy storage. A better energy efficiency and cruise performance of the ACHEON propelled aircraft can be obtained by decreasing cruise speed to about $324 \mathrm{~km} / \mathrm{h}(90 \mathrm{~m} / \mathrm{s})$. Data in this case indicates increase to $40 \mathrm{~min}$ cruise speed.

Assuming average European electric production efficiency [49], which has been estimated about $50 \%$ in 2010 , the effective energy demand will be about double than declared consumptions, but much lower than the one for the conventional engine.

\subsection{Improving the airplane configuration}

Improved performance can be ensured by equipping the plane by an electric lightweight cogeneration system coupled to heat recovery system. Assum Rolls Royce-Allison Model 250 C20R turboprop [49] with a max nominal power of about $190 \mathrm{~kW}$ and continuous power about $170 \mathrm{~kW}(602.5 \mathrm{MJ})$ is considered [50]. It has a weight of $62 \mathrm{~kg}$ dry $(0.32 \mathrm{~kg} / \mathrm{kW})$.
Considering all the necessary accessories a weight about $1.2 \mathrm{~kg} / \mathrm{kW}$ can be conservatively assumed, including the heat recovery system. Assuming the hypothesis of recovering heat from the turboprop and converting it by heating the fluid flow, preliminarily conceived by Trancossi [31], patented by Dumas et al. [51] and studied by Trancossi et al. [32]. Using the same calculation methodology used by Trancossi et al., thermal emission can be calculated by considering consumption about $0.48 \mathrm{~kg} / \mathrm{kWh}$ and a conservative global thermal exchange efficiency about 0.4 The amount of recovered heat per hour is then 338.65 $k W h(1220 \mathrm{MJ})$.

It means an increase in terms of thrust about $30 \%$ that means a reduction of required electrical power about $54 \mathrm{~kW}$.

This new condition enables flight with a partial system redefinition and general improve, with overall energy efficiency about three times the one of the traditional airplane.

In this case, it can be assumed the following configuration $250 \mathrm{~kg}$ of fuel, $250 \mathrm{~kg}$ cogeneration system and $1050 \mathrm{~kg}$ batteries.

This configuration could allow flight endurance about $6 \mathrm{~h}$ with a sufficient reserve,

This result is also interesting because the heat exchanger produces some losses but can be also used as a stator for straightening the jet as demonstrated by Shyam and Trancossi, which increases the adhesion, but also a positive thermal difference is a benefit because of an increased adhesion capability as demonstrated by Subhash in his thermal analysis.

The resulting configuration is summarized in Table 10.

The operational reduction of payload, which has been assumed in previous all electric architecture is maintained.

\section{(a)}

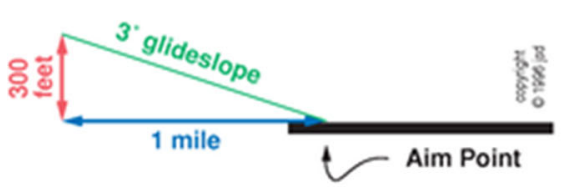

(b)

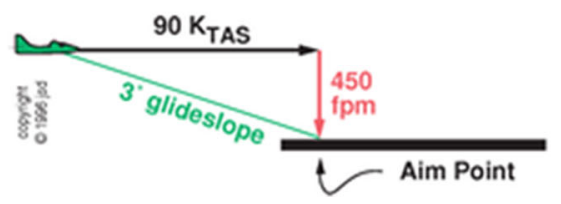

(c)

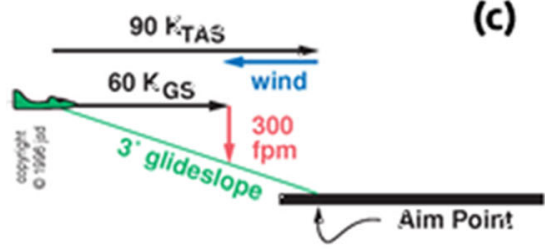

Fig. 20 Different gliding landing modes: a $3^{\circ}$ glideslope; $\mathbf{b} 3^{\circ}$ glideslope in absence of wind; $\mathbf{c} 3^{\circ}$ glideslope in presence of wind 
Table 7 Landing, Airspeeds and Angles with ACHEON

\begin{tabular}{|c|c|c|c|c|c|c|c|}
\hline & & & $\begin{array}{l}\text { Airspeed } \\
\text { (KCAS) }\end{array}$ & $\begin{array}{l}\text { Pitch } \\
\text { Attitude }\end{array}$ & Incidence & $\begin{array}{l}\text { Angle of } \\
\text { Climb }\end{array}$ & $\begin{array}{l}\text { Angle of } \\
\text { Attack }\end{array}$ \\
\hline Cruise (clean) & & & $100 \div 120$ & $0.0^{\circ}$ & $4.5^{\circ}$ & $0.0^{\circ}$ & $4.5^{\circ}$ \\
\hline Level VY (clean) & & & 70 & $4.0^{\circ}$ & $4.5^{\circ}$ & $0.0^{\circ}$ & $8.5^{\circ}$ \\
\hline Level (flaps) & & & 70 & $0.0^{\circ}$ & $8.5^{\circ}$ & $0.0^{\circ}$ & $8.5^{\circ}$ \\
\hline Slower (flaps) & & & $40 \div 65$ & $2.0^{\circ}$ & $8.5^{\circ}$ & $0.0^{\circ}$ & $10.5^{\circ}$ \\
\hline Descent (flaps) & & & $40 \div 65$ & $-2.0^{\circ}$ & $8.5^{\circ}$ & $-3.0^{\circ} \div-12.0^{\circ}$ & $10.5^{\circ}$ \\
\hline Flare (flaps) & & & decr. & incr. & $8.5^{\circ}$ & Incr. & incr. \\
\hline \multirow{4}{*}{$\begin{array}{l}\text { Stall (flaps) for different } \\
\text { angles of thrust } \\
\text { (half power angle) }\end{array}$} & $0^{\circ}$ & $0^{\circ}$ & 46.3 & $12.0^{\circ}$ & $8.5^{\circ}$ & $0.0^{\circ}$ & $20.5^{\circ}$ \\
\hline & $5^{\circ}$ & $10^{\circ}$ & 39.5 & $12.0^{\circ}$ & $8.5^{\circ}$ & $0.0^{\circ}$ & $20.5^{\circ}$ \\
\hline & $10^{\circ}$ & $20^{\circ}$ & 32.9 & $12.0^{\circ}$ & $8.5^{\circ}$ & $0.0^{\circ}$ & $20.5^{\circ}$ \\
\hline & $15^{\circ}$ & $30^{\circ}$ & 26.3 & $12.0^{\circ}$ & $8.5^{\circ}$ & $0.0^{\circ}$ & $20.5^{\circ}$ \\
\hline
\end{tabular}

\section{Conclusions}

This paper has clearly demonstrated the benefits of the ACHEON nozzle applied to the propulsion of a commuter class transport twin-engine aircraft. The choice has been focused on the Cessna 402 aircraft because its geometric conformation, which could easily allow a positioning of the ACHEON nozzle with centre of thrust almost coincident with centre of mass. The paper produces the basic control equations of an aircraft with this singularity showing the benefits of variable direction thrust applied in this position.
For simplicity only three positions have been considered, because they seems the state that can be easily produced at this level of research activity. They are full thrust (two fans on) with an angle $\mathrm{t}$ of inclination (with $t$ comprised between $0^{\circ}$ and $15^{\circ}$. A nozzle with opening equal to $t$ so that two extreme positions could be stabile:

- $0^{\circ}$ for horizontal flight, with higher jet near $100 \%$ ant the other below $50 \%$.

- $2 \mathrm{t}$ for takeoff operations to sustain the airplane during operations with lower jet about $100 \%$ and lower below $50 \%$.
Table 8 Landing performances in different configurations

\begin{tabular}{|c|c|c|c|c|c|c|c|c|}
\hline $\begin{array}{c}\text { Inclination of } \\
\text { the nozzle }\end{array}$ & 15 & & 10 & & 5 & & $0^{\circ}$ & \\
\hline Nozzle angle & 15 & & 10 & & 5 & & $0^{\circ}$ & deg \\
\hline \multirow[t]{2}{*}{ Direction of thrust } & 30 & & 20 & & 10 & & 0 & deg \\
\hline & $\mathrm{Tx}$ & Ty & $\mathrm{Tx}$ & Ty & $\mathrm{Tx}$ & Ty & $\mathrm{Tx}$ & \\
\hline Thrust & 2245.17 & 1296.25 & 2436.15 & 886.69 & 2553.11 & 450.18 & 2592.50 & $\mathrm{~kg}$ \\
\hline Max Power & 140 & & & & & & & $\mathrm{~kW}$ \\
\hline $\mathrm{u}_{\text {stall }}$ & 26.3 & & 32.9 & & 39.5 & & 46.3 & $\mathrm{~m} / \mathrm{s}$ \\
\hline $\mathrm{u}_{\text {stall,carriage, down }}$ & 18 & & 22.6 & & 27.1 & & 31.7 & ù \\
\hline Landing mass & 3105 & & & & & & & $\mathrm{~kg}$ \\
\hline Gliding Speed & 32.875 & & 41.125 & & 49.375 & & 55.56 & $\mathrm{~m} / \mathrm{s}$ \\
\hline Touch down Speed & 28.93 & & 36.19 & & 43.45 & & 50.93 & $\mathrm{~m} / \mathrm{s}$ \\
\hline $\begin{array}{l}\text { Landing Space } \\
\text { (calculated) }\end{array}$ & 431.71 & & 540.04 & & 648.38 & & 760 & $\mathrm{~m}$ \\
\hline $\begin{array}{l}\text { Average landing } \\
\text { acceleration }\end{array}$ & 2.03 & & 2.03 & & 2.03 & & 2.03 & $\mathrm{~m} / \mathrm{s} 2$ \\
\hline Landing Time & 14.25 & & 20.26 & & 24.32 & & 2.00 & $\mathrm{~s}$ \\
\hline Ground roll Time & 14.25 & & 17.83 & & 21.40 & & 25.09 & $\mathrm{~s}$ \\
\hline Braking Energy & 2598.71 & & 4066.67 & & 5861.94 & & 8053.95 & $\mathrm{~kJ}$ \\
\hline Braking energy & 1559.23 & & 2440.00 & & 3517.16 & & 4832.37 & $\mathrm{~kJ}$ \\
\hline $\begin{array}{l}\text { Braking Energy } \\
\text { saving }\end{array}$ & 3273.14 & & 2392.37 & & 1315.21 & & 0 & $\mathrm{~kJ}$ \\
\hline Energy saving & $40.64 \%$ & & $29.70 \%$ & & $16.33 \%$ & & 0 & $\%$ \\
\hline
\end{tabular}


Table 9 Energy performances

\begin{tabular}{|c|c|c|c|c|c|c|}
\hline \multirow[b]{3}{*}{ Flight Condition: } & \multicolumn{5}{|c|}{ Configuration } & \\
\hline & \multirow{2}{*}{$\begin{array}{l}\text { Cessna } 402 \\
\text { traditional }\end{array}$} & \multicolumn{4}{|c|}{ Cessna 402 ACHEON } & \\
\hline & & $15^{\circ}$ & $10^{\circ}$ & $5^{\circ}$ & $0^{\circ}$ & \\
\hline Take-Off & 132012 & 27468 & 31068 & 34668 & 44280 & $\mathrm{~kJ}$ \\
\hline Second Take-Off Segment & 504000 & 139100 & & & & $\mathrm{~kJ}$ \\
\hline Enroute (30 min) & 1908000 & 636000 & & & & $\mathrm{~kJ}$ \\
\hline Approach Segment & 267120 & 53000 & & & & $\mathrm{~kJ}$ \\
\hline Landing Segment & 396036 & 8240 & 9320 & 10400 & 13284 & $\mathrm{~kJ}$ \\
\hline Energy consumption & 3207168 & 863808 & 868488 & 873168 & 885664 & $\mathrm{~kJ}$ \\
\hline Max on board energy & 0 & 1229580 & & & & $\mathrm{~kJ}$ \\
\hline Reserve & -3207168 & 365772 & 361092 & 356412 & 343916 & $\mathrm{~kJ}$ \\
\hline
\end{tabular}

Kinematic and dynamic main parameters have been estimated during critical operations such as take off and landing verifying the benefits produced by the ACHEON nozzle in different flight condition. It appears fundamental, even if not directly presented in the paper, the importance of DBD to

Table 10 Modified Cessna 402 Cogeneration Architecture for high energy performances

\begin{tabular}{|c|c|c|}
\hline Empty weight & $\mathrm{Lb}$ & 4,069 \\
\hline Useful load & $\mathrm{Kg}$ & 662 \\
\hline Max takeoff weight & $\mathrm{Kg}$ & 3107 \\
\hline \multirow[t]{6}{*}{ Max on board fuel } & \multicolumn{2}{|c|}{$\begin{array}{l}\text { Batteries (Boston Power Swing }{ }^{\circledR} 5300 \\
\text { Rechargeable Lithium-ion Cell) }\end{array}$} \\
\hline & $\mathrm{Kg}$ & 1050 \\
\hline & $\mathrm{Wh} / \mathrm{kg}$ & 207 \\
\hline & $\mathrm{Ah}$ & 4,420 \\
\hline & \multicolumn{2}{|l|}{ Fuel } \\
\hline & $\mathrm{Kg}$ & 640 \\
\hline \multicolumn{3}{|l|}{ Propulsion } \\
\hline Cogen & \multicolumn{2}{|c|}{ Rolls Royce Model 250} \\
\hline Power & $\mathrm{kW}$ & 250 \\
\hline Mass & $\mathrm{Kg}$ & 250 \\
\hline Motor & \multicolumn{2}{|c|}{$\begin{array}{l}\text { Four Plettemberg Nov. } 150 \text { mounted } \\
\text { in two ACHEON Nozzle }\end{array}$} \\
\hline Power & $\mathrm{kW}$ & 150 \\
\hline Mass & $\mathrm{Kg}$ & 11.5 \\
\hline \multicolumn{3}{|l|}{ Performances } \\
\hline Max speed & $\mathrm{m} / \mathrm{s}$ & 118.9 \\
\hline Max cruising speed & $\mathrm{m} / \mathrm{s}$ & 109.4 \\
\hline Stall Speed & $\mathrm{m} / \mathrm{s}$ & 46.3 \\
\hline Stall Speed Carriage & $\mathrm{m} / \mathrm{s}$ & 25.1 \\
\hline Initial rate of climb & $\mathrm{m} / \mathrm{s}$ & 7.366 \\
\hline Service ceiling & M & 8200 \\
\hline Long range cruising speed & $\mathrm{m} / \mathrm{s}$ & 84.4 \\
\hline $\begin{array}{l}\text { Range with reserves at } \\
\text { economical cruising speed }\end{array}$ & $\mathrm{km}$ & 2000 \\
\hline
\end{tabular}

ensure an effective governable transition between the positions to avoid both too fast modifications of the airplane behaviour with potential stability problems and the actual considered capacity of producing thrust in three well-defined directions.

In particular, further application could benefit from the preliminary definition of a possible single jet architecture, which aims to reduce the problems derived from high frontal section required by the dual jet configuration.

A preliminary airplane configuration equipped by high performance batteries is presented.

Energetic evaluations have been performed demonstrating clearly the advantages of the proposed all electric system because of much higher energy conversion efficiency and because of the possibility, which has been presented to define a cogeneration airplane architecture equipped by a Rolls-Royce Model 250 turboprop based cogeneration unit. The large disposability in terms of heat to be dispersed could ensure the possibility of producing a more effective propulsion effect by using them to heat the jets produced by the ducted fans.

The clear advantages of the cogeneration based solution against the battery only one is evident demonstrating the possibility of an effective applicability of ACHEON all electric propulsion in the future, with a cogeneration based propulsion architecture.

In conclusion, this paper demonstrates the benefits of ACHEON based architecture to civil aircrafts ensuring enhanced performance. Even if it is not still sufficient for future ACHEON equipped aircrafts it is a preliminary basis for continuing the studies on ACEHON through a novel class of all electrical high performance aircraft, which could not been conceived before this revolutionary project.

Acknowledgments The present work has been performed as part of ACHEON Project | ACHEON Project - Aerial Coanda High Efficiency Orienting-jet Nozzle project, with ref. 309041 supported by European Union through the 7th Framework Programme (www.acheon.eu). 
Annex

Table 11 Aircrat data sheet

\begin{tabular}{|c|c|c|c|c|c|}
\hline \multicolumn{6}{|l|}{ Geometric data } \\
\hline Wing span & \multicolumn{2}{|l|}{$\mathrm{m}$} & 13.45 & $\mathrm{Ft}$ & 44.2 \\
\hline Length & \multicolumn{2}{|l|}{$\mathrm{m}$} & 11.09 & $\mathrm{Ft}$ & 36.5 \\
\hline Height & \multicolumn{2}{|l|}{$\mathrm{m}$} & 3.49 & $\mathrm{Ft}$ & 11.6 \\
\hline Wing Area & \multicolumn{2}{|l|}{$\mathrm{m}^{2}$} & 21 & $\mathrm{Sq} \mathrm{ft}$ & 225.8 \\
\hline \multicolumn{6}{|c|}{ Aerodynamic constants } \\
\hline $\mathrm{CD}$ & \multicolumn{2}{|l|}{ - } & \multicolumn{3}{|l|}{0.026} \\
\hline $\mathrm{E}$ & \multicolumn{2}{|l|}{-} & \multicolumn{3}{|l|}{0.85} \\
\hline $\mathrm{C}_{\mathrm{Lmax}}$ & \multicolumn{2}{|l|}{-} & \multicolumn{3}{|l|}{2.27} \\
\hline \multicolumn{3}{|l|}{ Weights } & \\
\hline Empty weight & \multicolumn{2}{|l|}{$\mathrm{kg}$} & 1845 & $\mathrm{Lb}$ & 4,069 \\
\hline Useful load & $\mathrm{kg}$ & 1262 & $\mathrm{Lb} \quad 2,783$ & $\mathrm{~kg} \quad 662$ & lb $\quad 1459.46$ \\
\hline Max takeoff weight & $\mathrm{kg}$ & & 3107 & $\mathrm{Lb}$ & 6,850 \\
\hline \multirow[t]{4}{*}{ Max on board fuel } & \multirow[t]{4}{*}{$\mathrm{kg}$} & 640 & \multirow[t]{4}{*}{ Gal 213} & \multicolumn{2}{|c|}{$\begin{array}{l}\text { Batteries (Boston Powe } \\
\text { Swing }{ }^{\circledR} 5300 \\
\text { Rechargeable } \\
\text { Lithium-ion Cell) }\end{array}$} \\
\hline & & & & $\mathrm{kg}$ & 1550 \\
\hline & & & & $\mathrm{Wh} / \mathrm{kg}$ & 170 \\
\hline & & & & $\mathrm{Ah}$ & 4,420 \\
\hline \multicolumn{6}{|l|}{ Propulsion } \\
\hline Engine & \multicolumn{3}{|c|}{$\begin{array}{l}\text { Two } 240 \mathrm{~kW}(325 \mathrm{hp}) \\
\text { turbocharged and } \\
\text { fuel injected TSIO- } \\
520-\mathrm{VBs}\end{array}$} & \multicolumn{2}{|c|}{$\begin{array}{l}\text { Four Plettemberg Nov. } \\
15 \text { mounted } \\
\text { in two ACHEON } \\
\text { Nozzle }\end{array}$} \\
\hline Power & $\mathrm{kW}$ & 240 & Hp 325 & kW 150 & hp 203 \\
\hline Weght & $\mathrm{kg}$ & 219.5 & $\mathrm{Lb} \quad 484$ & $\mathrm{~kg} \quad 11.5$ & lb 25.4 \\
\hline \multicolumn{6}{|l|}{ Performances } \\
\hline Max speed & \multicolumn{2}{|l|}{$\mathrm{m} / \mathrm{s}$} & 118.9 & Kts & 230 \\
\hline Max cruising speed & $\mathrm{m} / \mathrm{s}$ & & 109.4 & Kts & 213 \\
\hline Stall Speed & $\mathrm{m} / \mathrm{s}$ & & 46.3 & Kts & 71.4 \\
\hline $\begin{array}{l}\text { Stall Speed } \\
\text { Carrriage }\end{array}$ & $\mathrm{m} / \mathrm{s}$ & & 25.1 & Kts & 48.9 \\
\hline Initial rate of climb & $\mathrm{m} / \mathrm{s}$ & & 7.366 & $\mathrm{ft} / \mathrm{min}$ & 1,450 \\
\hline Service ceiling & $\mathrm{m}$ & & 8200 & $\mathrm{Ft}$ & 26,900 \\
\hline $\begin{array}{l}\text { Long range cruising } \\
\text { speed }\end{array}$ & $\mathrm{m} / \mathrm{s}$ & 84.4 & Kts 164 & To be calcu & ulated \\
\hline $\begin{array}{l}\text { Range with reserves } \\
\text { at economical } \\
\text { cruising speed }\end{array}$ & $\mathrm{km}$ & 2360 & $\mathrm{Nm} 1273$ & To be calc & ulated \\
\hline
\end{tabular}

Open Access This article is distributed under the terms of the Creative Commons Attribution 4.0 International License (http:// creativecommons.org/licenses/by/4.0/), which permits unrestricted use, distribution, and reproduction in any medium, provided you give appropriate credit to the original author(s) and the source, provide a link to the Creative Commons license, and indicate if changes were made.

\section{References}

1. Sehra AK (2003) Novel propulsion and power concepts for 21st century aviation. AVT Spring 2003 Symposium and Panel Business Week, Brussels

2. Trancossi M, Dumas A (2011) ACHEON: Aerial Coanda high efficiency orienting-jet nozzle. Sae Technical Papers N. 2011-012737, ISSN 0148-7191

3. Cen Z, Smith T, Stewart P, and Stewart J. Integrated flight/thrust vectoring control for jet-powered unmanned aerial vehicles with ACHEON propulsion. Proc Inst Mech Eng Part G: J Aerospace Eng 0954410014544179, first published on July 29, 2014 doi:10. 1177/0954410014544179

4. Trancossi M (2011) An overview of scientific and technical literature on coanda effect applied to nozzles. SAE Technical Papers N. 2011-01-2591, ISSN 0148-7191

5. Baffigi F, Dumas A, Giuliani I, Madonia M, Trancossi M (2014) Ugello capace di deviare in modo dinamico e controllabile un getto sintetico senza parti meccaniche in movimento e relativo sistema di controllo. Patent IT 0001406404, Deposito RE2011A000049, Filling date July 01, 2011, Publication date September 30, 2011, approved on February 21, 2014

6. Baffigi F, Dumas A, Giuliani I, Madonia M, Trancossi M (2014) Nozzle capable of deviating a synthetic jet in a dynamic and controllable manner with no moving mechanical parts and a control system thereof. PTC Patent WO2013005132 A1, Publication date Jan 10, 2013, Filing date Jun 25, 2012, Priority date Jul 1, 2011, Published also as EP2726213A1, US20140191059

7. Trancossi M, Dumas A (2011) Coanda syntetic jet deflection apparatus and control. SAE Technical Papers N. 2011-01-2590

8. Trancossi M, Dumas A (2011) ACHEON: Aerial Coanda High Efficiency Orienting-Jet Nozzle. Sae Technical Papers N. 2011$01-2737$

9. Cattafesta LN, Sheplak M (2011) Actuators for active flow control. 43(1): 247-272

10. Xisto C, Páscoa J, and Oliveira P (2013) Modelling plasma flow on a self-field MPD thruster using a PISO based method. 44th AIAA Plasmadynamics and Lasers Conference, San Diego, USA

11. Dragan V (2014) Reynolds number calculation and applications for curved wall jets. INCAS Bull 6(3):35-41

12. Dumas A, Pascoa J, Trancossi M, Tacchini A, Ilieva G, Madonia M (2012) Acheon project: A novel vectoring jet concept. Proc. ASME. 45172; Volume 1: Advances in Aerospace Technology: 499-508, IMECE2012-87638

13. Trancossi M, Dumas A, Vucinic D (2013) Mathematical modelling of coanda effect. SAE Technical Paper 2013-01-2195, doi:10.4271/ 2013-01-2195

14. Drăgan V (2012) A New mathematical model for Coandă effect velocity approximation. INCAS Bull 4:85-92

15. Subhash M, Dumas A (2013) Computational study of Coanda adhesion over curved surface. SAE Int J Aerosp 6(1):260-272. doi: 10.4271/2013-01-2302

16. Dumas A, Subhash M, Trancossi M, Marques JP (2014) The influence of surface temperature on Coanda effect. Energy Proc 45:626634

17. Das SS, Abdollahzadeh M, Pascoa JC, Dumas A, Trancossi M (2014) Numerical modelling of Coanda effect in a novel propulsive system. Int J Multiphys 8(2):181-201

18. Trancossi M, Subhash M, Angeli D (2013) Mathematical modelling of a two streams Coanda effect nozzle. ASME Int. Mech. Engg. Conf. and Exhibition, paper no. IMECE2013-63459 
19. Trancossi M, Dumas A, Das SS, Páscoa JC (2014) Design methods of Coanda nozzle with two streams. INCAS Bull 6 (1); 83-95, ISSN 2066-8201, doi: 10.13111/2066-8201.2014.6.1.8

20. Pascoa JC, Dumas A, Trancossi M, Stewart P, Vucinic D (2013) A review of thrust-vectoring in support of a V/ STOL non-moving mechanical propulsion system. Cent Eur J Eng 3(3):374-388

21. Páscoa JC, Brójo FMP, Monteiro JMM (2009) Numerical simulation of magneto-plasma thrusters for aerospace propulsion using and MHD formulation. Paper O-7.2, Proc. 14th International Conference on Emerging Nuclear Energy Systems, Instituto Tecnológico e Nuclear, 6 pgs

22. Abdollahzadeh M, Pascoa J (2014) Modified split-potential model for modelling the effect of DBD plasma actuators in high altitude flow. Control Current Applied Physics

23. Abdollahzadeh M, Páscoa JC, Oliveira PJ (2014) Two-dimensional numerical modelling of interaction of micro-shock wave generated by nanosecond plasma actuators and transonic flow. J Comput Appl Math 270:401-416

24. Suñol A, Vucinic D (2014) Numerical analysis and UAV application of the ACHEON vectorial thrust nozzle. 32nd AIAA Applied Aerodynamics Conference. June 2014. doi: 10.2514/6.2014-2046

25. European Parliament and European Council (2008), Reg. (EC) No 216/2008 of the on common rules in the field of civil aviation and establishing a European Aviation Safety Agency, and repealing Council Directive 91/670/EEC, Regulation (EC) No 1592/2002 and Directive 2004/36/EC, Eurlex, European Union

26. Wolowiczc CH (1972) Longitudinal aerodynamic characteristics of light, twin-engine, propeller-driven airplanes. Nasa Technical Notes 6800, June 1972, NASA

27. Nicolosi F, Della Vecchia P, Corcione S (2012) Aerodynamic analysis and design of a twin engine commuter aircraft. Procedings of ICAS 2012, International Council of the Aeronautical Sciences, Brisbane, Australia

28. Roskam J (2000) Airplane design, part VI: preliminary calculation of aerodynamic, thrust and power characteristics, 2nd edn. DARcoporation, Lawrence

29. Frlschtak CR (2000) Learning, technical progress and competitiveness in the commuter aircraft industry: an analysis of embrarer. The World Bank, June, 1992

30. Williams JP (1983) Small transport aircraft technology. NASA SP460, 1983

31. Trancossi M, Pascoa J (2013) Thermojet: an old idea can define a novel family of jets. SAE Technical Paper 2013-01-2205, doi:10. 4271/2013-01-2205

32. Trancossi M, Dumas A, Stewart P, Vucinic D (2014) Increasing aeronautic electric propulsion performances by cogeneration and heat recovery. SAE Technical Paper 2014-01-2106, doi:10.4271/ 2014-01-2106

33. Mingtai C (2012) Static thrust measurement for propeller-driven light aircraft, the 2 nd international conference on computer application and system modelling. Taiyuan Institute of Science and Technology, Taiyuan. ISBN 978-94-91216-00-8
34. Keen EB (2004) A conceptual design methodology for predicting the aerodynamics of upper surface blowing on airfoils and wings. MS. Thesys, Virginia Polytechnic Institute \& State University

35. FAR 25.105 - Takeoff, FAA, Doc. No. 5066, 29 FR 18291, Dec. 24, 1964, as amended by Amdt. 25-92, 63 FR 8318, Feb. 18, 1998; Amdt. 25-121, 72 FR 44665, Aug. 8, 2007

36. FAR 25.107 - Takeoff Speeds, FAA, Doc. No. 5066, 29 FR 18291, Dec. 24, 1964, as amended by Amdt. 25-38, 41 FR 55466, Dec. 20, 1976; Amdt. 25-42, 43 FR 2320, Jan. 16, 1978; Amdt. 25-92, 63 FR 8318, Feb. 18, 1998; Amdt. 25-94, 63 FR 8848, Feb. 23, 1998; Amdt. 25-108, 67 FR 70826, Nov. 26, 2002; Amdt. 25-121, 72 FR 44665, Aug. 8, 2007; Amdt. 25-135, 76 FR 74654, Dec. 1, 2011

37. FAR 25.109 - Accelerate-stop distance, FAA, Doc. No. 5066, 29 FR 18291, Dec. 24, 1964, as amended by Amdt. 25-42, 43 FR 2321, Jan. 16, 1978; Amdt. 25-92, 63 FR 8318, Feb. 18, 1998

38. FAR 25.111 - Takeoff path, FAA, Doc. No. 5066, 29 FR 18291, Dec. 24, 1964, as amended by Amdt. 25-6, 30 FR 8468, July 2, 1965; Amdt. 25-42, 43 FR 2321, Jan. 16, 1978; Amdt. 25-54, 45 FR 60172, Sept. 11, 1980; Amdt. 25-72, 55 FR 29774, July 20, 1990; Amdt. 25-94, 63 FR 8848, Feb. 23, 1998; Amdt. 25-108, 67 FR 70826, Nov. 26, 2002; Amdt. 25-115, 69 FR 40527, July 2, 2004; Amdt. 25-121, 72 FR 44666; Aug. 8, 2007

39. FAR 25.113 - Takeoff distance and takeoff run, FAA, Doc. No. 5066, 29 FR 18291, Dec. 24, 1964, as amended by Amdt. 25-23, 35 FR 5671, Apr. 8, 1970; Amdt. 25-92, 63 FR 8320, Feb. 18, 1998

40. FAR 25.115 - Takeoff flight path, FAA, Doc. No. 5066, 29 FR 18291, Dec. 24, 1964, as amended by Amdt. 25-92, 63 FR 8320, Feb. 18, 1998

41. FAR 25.119 - Landing climb: all-engines-operating, FAA, Amdt. 25-121, 72 FR 44666; Aug. 8, 2007

42. FAR 25.125 - Landing, FAA, Amdt. 25-121, 72 FR 44666; Aug. 8, 2007; 72 FR 50467, Aug. 31, 2007

43. Anderson JD (2000) Introduction to flight, 4th edn. McGraw-Hill, Boston, $766 \mathrm{p}$

44. VV AA (xxxx) Cessna 402 User manual, Cessna Corporation

45. Phase P (1993) Take off \& landing performance. USAF Test Pilot School, Edwards AFB, California, www.dtic.mil/dtic/tr/fulltext/u2/ a320210.pdf

46. Trancossi M, Madonia M (2012) The efficiency of an electric turbofan vs. inlet area: a simple mathematical model and CFD simulations. SAE Technical Paper 2012-01-2217

47. Taylor M (1989) Jane's encyclopedia of aviation. Studio Editions, London

48. Cessna (2007) Type Certificate data sheet no. A7CE, FAA, Wichita Certification Office, Revision 47, CESSNA, March 27, 2007

49. VV AA (2008) Energy efficiency indicators for public electricity production from fossil fuels. International Energy Agency, Paris

50. Pegors D (1987) Advanced Allison small turboprop engines. SAE Technical Paper 871055. doi:10.4271/871055

51. Dumas A, Niccolai G, Trancossi M, Vucinic D. Aeromobile con prestazioni incrementate mediante sistema di propulsione cogenerativo, IT Patent request n. RE2014A000022 